\title{
Terminalidade Específica nos Institutos Federais: um panorama
}

\author{
Specific Terminality at Federal Institutes: an overview
}

Terminalidad Específica en los Institutos Federales: un panorama

\author{
Wanessa Moreira de Oliveira \\ Doutoranda no Instituto Oswaldo Cruz/Fiocruz, Rio de Janeiro, Rio de Janeiro, Brasil. \\ oliverwanessa85@gmail.com \\ ORCID - https://orcid.org/0000-0002-8679-3296

\section{Cristina Maria Carvalho Delou} \\ Professora doutora aposentada da Universidade Federal Fluminense, Niterói, Rio de Janeiro, Brasil. \\ cristinadelou@gmail.com \\ ORCID - https://orcid.org/0000-0001-9206-6004
}

Recebido em 3 de março 2020

Aprovado em 24 de agosto de 2020

Publicado em 30 de setembro de 2020

\section{RESUMO}

O presente estudo propõe-se a discutir a questão da Terminalidade Específica (TE) para estudantes com deficiência intelectual/múltipla, prevista na política educacional, com o intuito de investigar sua adoção no âmbito dos Institutos Federais de Educação, Ciência e Tecnologia (IFs). Trata-se de uma pesquisa de natureza qualitativa, desenvolvida por meio de documentos que constam nos sites oficiais e informações disponibilizadas pelos IFs no Sistema Eletrônico do Serviço de Informação ao Cidadão. Os dados foram explorados por meio da análise de conteúdo de Bardin (1977). Após o levantamento das previsões normativas da TE e dos documentos e informações dos IFs, foi realizada préanálise documental, através da qual identificaram-se duas categorias de organização temática do estudo. Dos 38 IFs pesquisados, foram identificadas práticas inclusivas documentadas em 34, regulamentação da TE em 13 e certificação de estudantes por TE em 6 IFs. As discussões indicaram compreensões dúbias sobre a TE. Os resultados evidenciaram que, apesar de poucos IFs terem regulamentado e/ou aplicado a TE, eles a têm assumido para a conclusão de uma etapa formativa profissional, declarando apenas as habilidades e competências alcançadas, na perspectiva de uma atuação profissional possível, mostrando à sociedade a incompletude da formação técnica profissional. Nesse sentido, ressalta-se a necessidade de promover mais discussões acerca do tema, assim como de estabelecer o papel que a TE deve ter na Educação Especial, considerando a Declaração de Incheon e a Lei Brasileira de Inclusão, que preveem educação ao longo da vida.

Palavras-chave: Deficiência intelectual/múltipla; Ensino Técnico Profissional; Educação ao longo da vida.

\section{ABSTRACT}

The present study proposes a discussion about Specific Terminality (ST) for students with intellectual/multiple disabilities, pre-established in educational politics, in order to investigate its adoption in the environment of the Federal Institutes of Education, Science, and Technology (FI). This is a qualitative research, developed through documents found 
on official sites and information provided by the FI in the Electronic System of Information to the Citizen. The data was explored by means of the content analysis of Bardin (1977). After the normative predictions survey about ST and documents and information from FI, it was performed a documental pre-analysis, through which identified two categories of thematic organization of study. From 38 Federal Institutes surveyed, it was identified inclusive practices in 34 institutions, regulation of ST in 13, and certification of students by ST in $6 \mathrm{FI}$. The discussions indicated dubious understanding about ST. The results reveal that, despite of few FI had regulated and/or applied ST, they have assumed it to the conclusion of aprofessional graduation stage, declaring only the abilities and competences achieved, from the perspective of a possible professional performance, showing to the society the incompleteness of the professional technical education. In this sense, it is emphasized the need to promote discussions about this topic, as well as to stablish the role that ST must have in the Special Education by considering the Incheon Declaration and the Brasilian Inclusion Law, which stablishes lifelong education.

Keywords: Intellectual/multiple disability; Professional Technical Education; Lifelong education.

\section{RESUMEN}

Esta investigación propone una discusión acerca de la Terminalidad Específica (TE) para estudiantes con discapacidad intelectual/múltiple, establecida en la política educativa, y tiene el propósito de examinar su adopción en el marco de los Institutos Federales de Educación, Ciencia y Tecnología (IFs). Se trata de una vía de investigación cualitativa, que se desarrolla por medio de documentos que figuran en la página oficial e informaciones facilitadas por los IFs en el Servicio Electrónico de Información al Ciudadano. Los datos se han extraído a través de análisis de contenido de Bardin (1977). Una vez se hayan levantado la previsión normativa de TE y de los documentos e informaciones de los IFs, se llevó a cabo un análisis documental previo, del cual se identificó dos categorías de organización temática del estudio. Se examinó 38 IFs, en los que se detectaron prácticas de inclusión documentadas en 34, regulación normativa de la TE en 13 y certificación de estudiantes de TE en 6 IFs. Las conclusiones apuntan una comprensión confusa sobre la TE. Los resultados han puesto de relieve que, aunque unos pocos IFs han regulado o aplicado la TE, ellos la han considerado para la conclusión de una etapa de formación profesional, declarando sólo las habilidades y competencias logradas, en la perspectiva de una posible actuación profesional, que muestra a la sociedad la limitación de la formación técnica profesional. Al respecto, se destaca la necesidad de fomentar más debates acerca del tema, así como establecer el papel de la TE en la Educación Especial, considerando la Declaración de Incheon y la Ley Brasileña de Inclusión, que establecen la educación permanente.

Palabras clave: Discapacidad intelectual/múltiple; Enseñanza Técnica-Profesional; Educación permanente.

\section{Introdução}

Contrariando a Convenção sobre os Direitos das Pessoas com Deficiência e seu Protocolo Facultativo (BRASIL, 2007; 2008; 2009), continua em vigor a Terminalidade Específica (TE), prevista na Lei de Diretrizes e Bases da Educação Nacional (LDBEN), 
http://dx.doi.org/10.5902/1984686X48006

para estudantes que "não puderem atingir o nível exigido para a conclusão do ensino fundamental, em virtude de suas deficiências, e aceleração para concluir em menor tempo o programa escolar para os superdotados" (BRASIL, 1996).

Regulamentada pelo Parecer do Conselho Nacional de Educação/ Câmara de Educação Básica (CNE/CBE) n. 17/2001 e pela Resolução CNE/CBE no. 2/2001, a TE é

certificação de conclusão de escolaridade - fundamentada em avaliação pedagógica - com histórico escolar que apresente, de forma descritiva, as habilidades e competências atingidas pelos educandos com grave deficiência mental ou múltipla. (BRASIL, 2001, p.28).

Direcionada aos estudantes que não alcançaram os resultados de escolarização previstos nos Arts. 24, 26 e 32 da LDBEN para o ensino fundamental, em relação ao "desenvolvimento da capacidade de aprender, tendo como meios básicos o pleno domínio da leitura, da escrita e do cálculo" (BRASIL, 1996), a TE foi prevista para estudantes que apresentem

associadas a grave deficiência mental ou múltipla, a necessidade de apoios e ajudas intensos e contínuos, bem como de adaptações curriculares significativas, não deve significar uma escolarização sem horizonte definido, seja em termos de tempo ou em termos de competências e habilidades desenvolvidas. (BRASIL, 2001, p. 28).

Segundo Nota Técnica (NT) nํ. 13/2009¹ (BRASIL, 2009a, apud BRASIL, 2015), emitida pela Secretaria de Educação Especial (SEESP) vinculada ao Ministério da Educação (MEC),

a terminalidade específica, a qual não significa certificação de conclusão do ensino fundamental, mas da escolaridade desenvolvida no ensino fundamental, possibilitando o encaminhamento para outras modalidades: a educação de jovens e adultos (primeiro segmento: ensino fundamental) e a educação profissional (qualificação profissional básica). (BRASIL, 2009a, apud BRASIL 2015, p. 149).

O texto da NT mostra que

a terminalidade específica do fundamental não permite o encaminhamento e continuidade dos estudos no ensino médio, considerando que não houve conclusão da etapa do fundamental. (BRASIL, 2009a, apud BRASIL, 2015, p. 149).

A TE impossibilita a progressão do estudante público da Educação Especial (EE), que apresenta grave deficiência intelectual (DI) ou deficiência múltipla (DM), para a etapa de escolaridade posterior, considerando que não houve avanço nas competências mínimas estabelecidas na etapa atual, após esgotadas as possibilidades de adaptações. 
http://dx.doi.org/10.5902/1984686X48006

Novas concepções surgiram com a aprovação da Convenção sobre os Direitos das Pessoas com Deficiência (BRASIL, 2007; 2008; 2009), as quais foram, mais recentemente, reforçadas com a adesão do Brasil à Declaração de Incheon (UNESCO, 2015) e com a publicação da Lei Brasileira de Inclusão (LBI) (BRASIL, 2015a).

Assim, a política educacional brasileira passa a evidenciar dois aspectos que se somam à discussão sobre a TE: a possibilidade de entendimento da TE como uma prática discriminatória de exclusão de estudantes da escola por motivo de deficiência e como uma prática impeditiva de realização de aprendizagens ao longo da vida.

Inicialmente, foi previsto que o público da EE que não atingisse os resultados preconizados na LDBEN poderia dar continuidade ao processo de escolarização na Educação de Jovens e Adultos (EJA) de ensino fundamental ou médio, por já terem ultrapassado a idade apropriada para conclusão nesta etapa, ou por meio de cursos de qualificação profissional que levassem em consideração a sua capacidade de aprender e não o nível de escolaridade. Em ambos os casos, seria considerado o suporte da EE, por meio do Atendimento Educacional Especializado (AEE), sendo garantido o cumprimento da Convenção que prevê "o reconhecimento, o gozo ou o exercício, em igualdade de oportunidades com as demais pessoas" (BRASIL, 2007, p. 17).

Ao contrário, os Pareceres Técnicos ${ }^{4}$ nำ 14/2009 e no 31/2009, emitidos pela SEESP/MEC (BRASIL, 2009b, 2009c, apud BRASIL, 2015), apontam que a TE não seria necessária, porque o fluxo do processo educacional está previsto na legislação e é realizado, na prática, pelas instituições de ensino sem ter que recorrer ao estatuto da TE, que é vulnerável à percepção discriminatória de exclusão por motivo de deficiência.

Havendo a possibilidade de acesso à educação por meio do encaminhamento de alunos maiores à modalidade de Educação de Jovens e Adultos, elimina-se a questão da terminalidade específica prevista na Lei no 9.394/96, considerando que os alunos com deficiência continuarão a ter direito ao atendimento educacional especializado em qualquer etapa, nível ou modalidade de educação e ensino. (BRASIL, 2009c, apud BRASIL, 2015, p. 199).

A LDBEN garante a todos os estudantes "históricos escolares, declarações de conclusão de série e diplomas ou certificados de conclusão de cursos, com as especificações cabíveis" (BRASIL, 1996), e a TE conceitua-se por meio de "histórico escolar que apresente, de forma descritiva, as habilidades e competências atingidas pelos educandos com grave deficiência mental ou múltipla" (BRASIL, 2001, p. 28). Logo, as 
http://dx.doi.org/10.5902/1984686X48006

especificações cabíveis podem compreender a descrição de habilidades e competências alcançadas para um público específico da EE: educandos com grave DI/DM.

Segundo lacono e Mori (2004), a maioria desses estudantes demandam adaptações curriculares significativas para serem inseridos no contexto de ensino regular, para avançarem nas séries subsequentes e terem terminalidade no ensino fundamental. Assim, independentemente do aproveitamento escolar dos estudantes com DI/DM no ensino fundamental, com ou sem TE, eles têm chegado ao ensino médio regular, conforme registram os dados do censo escolar de 2019 (INEP, 2020).

A inexistência de uma orientação clara sobre a prática da TE, a falta de debates sobre o tema nos espaços de ensino e a ocorrência de poucas discussões nas produções acadêmicas (IACONO e MORI, 2004; LIMA, 2009; ELIAS et al., 2012; SILVA, 2016; MILANESI e MENDES, 2016; PERTILE e MORI, 2018; SANTOS, 2019; SILVA e PAVÃO, 2019) mostram que muitas escolas têm certificado a conclusão da etapa escolar de estudantes público da EE mesmo sem o desenvolvimento mínimo das habilidades e competências requeridas, ora certificando com TE, ora concedendo o certificado de conclusão não diferenciado.

Assim, quando concedida, a TE tem representado a certificação de conclusão de uma etapa formativa e não apenas a certificação da escolaridade efetivamente desenvolvida até então, conforme entendimento registrado pela SEESP/MEC (BRASIL, 2009a, 2009b, 2009c, apud BRASIL, 2015).

A preocupação demarcada por alguns Institutos Federais de Educação, Ciência e Tecnologia (IFs) sobre a adoção da TE na formação profissional, registrada em consultas direcionadas ao CNE (BRASIL, 2013; 2015) e em estudos recentes (PERTILE e MORI, 2018; SANTOS, 2019), demonstra que estudantes passíveis de TE também têm ingressado em cursos técnicos de nível médio e de educação superior (SILVA e PAVÃO, 2019).

Entretanto, algumas vezes, esses estudantes têm chegado aos IFs sem considerar as habilidades mínimas necessárias para a continuidade progressiva da aprendizagem nos cursos de formação profissional, que respondem a padrões definidos na Classificação Brasileira de Ocupações (BRASIL, 2020), no Catálogo Nacional de Cursos Técnicos (BRASIL, 2014) e no Catálogo Nacional de Cursos Superiores de Tecnologia (BRASIL, 2016). Tal situação pode ser observada na exposição feita pelo $\mathrm{IFES}^{5}$, em consulta ao 
http://dx.doi.org/10.5902/1984686X48006

CNE, sobre a possibilidade de aplicação do estatuto da TE aos cursos técnicos de nível médio, apontando razões para a reflexão.

\footnotetext{
Os requerentes argumentam que não é a primeira vez que eles constatam, no Espírito Santo, a existência da aprovação automática dos alunos da Educação Especial, como uma forma deturpada da aplicação da chamada "terminalidade específica", seja por desconhecimento, seja pelo mais genuíno descumprimento da lei. (BRASIL, 2013, p. 2).
}

Dessa forma, estudantes com grave DI/DM certificados por TE no ensino fundamental, muitas vezes, ao invés de serem encaminhados para EJA e/ou para cursos de qualificação profissional ao nível de suas condições básicas, têm sido encaminhados para o ensino médio, inclusive na modalidade integrada a cursos técnicos de maior complexidade formativa.

Tal situação pode constituir-se em um desafio para os IFs que oferecem cursos técnicos de nível médio nas formas integrada, concomitante ou subsequente, entre outras modalidades de ensino, exigindo um repensar de suas práticas educacionais.

Em geral, o acesso de estudantes com deficiência tem aumentado nos IFs, seja em razão da expansão e interiorização de suas unidades, seja pela implementação de ações afirmativas, estabelecidas pela Lei de Cotas (BRASIL, 2012; 2016a), sem considerar a condição de estudantes com deficiência que concluíram a etapa anterior de ensino por TE.

Assim, os IFs ficam suscetíveis a receberem estudantes que não desenvolveram minimamente os conteúdos previstos na etapa de ensino anterior, o que pode confundir a condição de deficiência com problemas de ensino e aprendizagem. E, aqui, não se trata de negar todos os benefícios sociais e humanitários que a escola, enquanto equipamento social que implementa a política de inclusão, trouxe a qualquer aluno que tenha conquistado o direito de uma vaga em qualquer IF. Trata-se de reconhecer a função de uma instituição de formação profissional, na qual habilidades e competências mínimas são imprescindíveis à formação do ofício para o qual os alunos foram selecionados. Não se resume apenas a garantia de cidadania, mas também de criação as condições ideais para a formação técnica profissional (BRASIL, 2014; 2016; 2020).

Diante do inusitado, os IFs têm recorrido à TE como alternativa para reconhecer o processo formativo de estudantes que foram certificados por ela no ensino fundamental e, em outros casos, que necessitam de processos pedagógicos diferenciados e adaptações 
http://dx.doi.org/10.5902/1984686X48006

tão significativas que não se sustentam como razoáveis (BRASIL, 2015a) para cursos de formação técnica profissional.

Aos IFs implica maior responsabilidade ao processo de certificação por terem a atribuição de reconhecer as aptidões de um profissional que foi capacitado para ingressar no trabalho, ou minimamente preparado para exercer uma profissão de acordo com os Projetos Pedagógicos dos Cursos, amparados em documentações específicas de cursos de formação técnica e profissional no Brasil (BRASIL, 2014; 2016; 2020).

A aplicação da TE, na Educação Profissional, foi problematizada por Pertile e Mori (2018), demarcando-se a diferença quanto à sua aplicação no ensino fundamental.

\begin{abstract}
A terminalidade específica teria na educação profissional uma característica diferente da que se podia esperar no Ensino Fundamental. Neste a finalização dessa etapa da Educação Básica se daria por meio da certificação. No Ensino Profissional, explicaria uma formação com apropriações diferenciadas e portanto, para um exercício profissional especificado a partir da individualidade do sujeito. Seria assim uma expressão em termos de certificação profissional após um processo de adaptações e adequações indispensáveis e que permitiram ao aluno a conclusão do curso. (PERTILE e MORI, 2018, p. 9).
\end{abstract}

A TE tem representado a possibilidade de finalização de uma etapa formativa nos IFs para que o estudante da EE possa prosseguir na formação profissional ou ser inserido em contextos de trabalho. Mas os que se encontram em situação de grave DI/DM, que não demonstram habilidades e competências mínimas para exercerem as práticas profissionais exigidas em legislação própria, apresentam condição inusitada que precisa ser considerada no âmbito da educação profissional.

O Parecer CNE/CEB no 5/2019 deu outra compreensão à TE, propondo uma certificação diferenciada, que reconhece o desenvolvimento alcançado pelo estudante público da EE, independente do previsto para a conclusão de curso de formação técnica e profissional, mas, ao mesmo tempo, certifica a conclusão da etapa formativa, com emissão de diploma profissional (BRASIL, 2019).

A proposta é louvável, na medida em que considera a necessidade de realizar um planejamento e acompanhamento individualizado do processo educacional do estudante público da EE, registrando e reconhecendo o seu desenvolvimento escolar efetivo. Contudo, conferir certificação de curso técnico e profissional a estudantes que, mesmo com a realização de adaptações razoáveis, não conseguiram desenvolver habilidades e competências mínimas requeridas para o exercício profissional pode implicar outras dificuldades na continuidade do processo educacional do discente e/ou em sua atuação 
http://dx.doi.org/10.5902/1984686X48006

profissional, assim como questões de responsabilidade jurídica frente aos órgãos de reconhecimento profissional.

Por outro lado, se não houver previsão de conclusão do processo formativo, mesmo que parcial ou diferenciado, para estudantes público da EE que requerem adaptações significativas nos cursos de formação profissional, até quando eles deverão permanecer na mesma etapa de ensino? Deverão ser reprovados em razão de não conseguirem desenvolver as competências previstas para a etapa em questão? Será implementada uma nova modalidade de curso, que responda à previsão da LBI (BRASIL, 2015a) de "aprendizado ao longo de toda a vida", para esses estudantes?

Assim, na falta de uma orientação clara e objetiva sobre os encaminhamentos e de consenso em relação à TE, os IFs fazem o que é possível para atender os estudantes público da EE dentro do princípio da razoabilidade (BRASIL, 2015a), conforme observa-se em registros de experiências inclusivas de IFs (SANTOS e PONCIANO, 2019; PEROVANO, 2019), seja organizando núcleos de apoio da EE, seja realizando adaptações pedagógicas e/ou flexibilizando currículos e prazos.

Para que não se corra o risco de descaracterizar a proposta da política de educação inclusiva, em decorrência de uma sucessão de equívocos, derivados de interpretações dúbias da legislação, resultantes da ausência de normativas objetivas sobre a TE, faz-se premente a reflexão e a revisão de seu Estatuto.

Assim, o presente estudo propõe-se a discutir a questão da TE para estudantes com DI/DM, prevista na política educacional, com o intuito de investigar sua adoção no âmbito dos IFs.

\section{Metodologia}

O presente estudo caracteriza-se como pesquisa exploratória na medida em que propõe-se dar maior clareza ao tema apresentado, possibilitando "proporcionar maior familiaridade com o problema, com vistas a torná-lo mais explícito ou a construir hipóteses" (GIL, 2002, p. 41). Do tipo documental, uma vez que apoia-se na análise de documentos, considerando que "constituem fonte rica e estável de dados" (GIL, 2002, p. 46). E de abordagem qualitativa (FLICK, 2009; MINAYO, 2015), já que busca responder às questões específicas de uma dada realidade, trabalhando na perspectiva dos motivos e significados (MINAYO, 2015, p. 21), possibilitando a apropriação de métodos e teorias, 
observação e análise de diferentes perspectivas, reflexão e pluralidade de abordagens e métodos (FLICK, 2009, p. 23).

A coleta de dados foi realizada através de consultas ao Sistema Eletrônico do Serviço de Informação ao Cidadão (e-Sic) ${ }^{6}$ e aos sites oficiais de cada um dos 38 IFs existentes no Brasil (BRASIL, 2019a). As consultas foram realizadas no período de novembro de 2019 a março de 2020, por meio da abertura de processo no e-Sic, solicitando informações sobre a regulamentação e aplicação da TE e da identificação de documentos institucionais ${ }^{7}$ que referenciassem as ações inclusivas e a TE disponíveis nos sites oficiais dos IFs. A busca nos sites ocorreu por meio da identificação do setor organizacional de referência das ações inclusivas e seus documentos disponíveis, e pela pesquisa, no canal de buscas de cada site, dos seguintes termos: Terminalidade Específica, Política de Inclusão e NAPNE.

Os dados coletados foram explorados a partir da análise de conteúdo de Bardin (1977), mediante leitura sistemática dos documentos institucionais e das respostas dos IFs identificadas na etapa de pré-análise, seguida da etapa de exploração do material, com organização de dados, tratamento das informações e codificação a partir dos conteúdos mais relevantes e comuns, possibilitando a identificação e organização de categorias e subcategorias temáticas a serem trabalhadas e interpretadas na etapa de tratamento dos resultados.

\section{Resultados e discussão}

A partir das etapas de pré-análise e de exploração do material coletado, previstas na análise de conteúdo (BARDIN, 1977), foram definidas duas categorias temáticas para o presente estudo, considerando a pertinência com os materiais de análise, buscando refletir as intenções da investigação e abarcar as questões/unidades de análise, identificadas na codificação do conteúdo (Quadro 1). 
Quadro 1 - Categorias de Análise

\begin{tabular}{|c|c|}
\hline \multirow{4}{*}{ CATEGORIAS TEMÁTICAS } & QUESTÕES/UNIDADES DE ANÁLISE \\
\hline \multirow{4}{*}{ A TE nos documentos institucionais dos IFs } & $\begin{array}{r}\text { Existem documentos que organizam as ações inclusivas } \\
\text { nos IFs? Quais? O que preveem? }\end{array}$ \\
\cline { 2 - 2 } & A TE está prevista? \\
\cline { 2 - 2 } & Como quem a TE destina-se? organiza-se? \\
\cline { 2 - 2 } & Existem estudantes certificados? Quais deficiências \\
A TE na prática dos IFs & apresentam? \\
\cline { 2 - 2 } & Quais modalidade de cursos tiveram estudantes \\
& certificados? \\
\cline { 2 - 2 } & Os estudantes certificados tiveram TE na etapa anterior \\
& de ensino? \\
\hline
\end{tabular}

Fonte: Autores (2020).

As unidades de análise, apresentadas em forma de questões, foram definidas a partir da decomposição e codificação dos conteúdos dos materiais, na etapa de exploração, expressando aspectos comuns e relevantes da temática que, por sua vez, orientaram as reflexões empreendidas em cada categoria temática.

\section{A TE nos documentos institucionais dos IFs}

Foram identificados e analisados $59^{8}$ documentos oficiais relacionados a ações de inclusão e atendimento aos discentes público da EE, entre políticas, planos/normativas de acessibilidade, regulamentos de núcleos de apoio e de atendimento especializado, propostos por $34(89,5 \%)$ IFs $^{9}$.

O exame pormenorizado desses registros documentais deu-se a partir da identificação e reflexão de pontos comuns e de conteúdos relevantes para o objetivo pretendido na investigação, na perspectiva da análise de conteúdo de Bardin (1977).

A exploração dos documentos permitiu confirmar o que demonstram estudos recentes sobre práticas inclusivas desenvolvidas em IFs (SANTOS e PONCIANO, 2019; 
PEROVANO, 2019): que as políticas inclusivas nessas instituições têm buscado oferecer recursos e serviços de apoio da EE, objetivando ampliar a participação dos estudantes público da EE nos processos de ensino e aprendizagem e favorecer sua formação profissional, organizando-se em torno da política de EE (BRASIL, 2008a).

Observa-se, assim, que grande parte dos IFs (89,5\%), apesar de não dispor de uma política ou programa de inclusão específico da Rede Federal ${ }^{10}$ (NASCIMENTO e FARIA, 2013; OLIVEIRA, 2017), tem organizado suas práticas inclusivas e institucionalizado núcleos de referência para $E E$.

Os Núcleos de Atendimento às Pessoas com Necessidades Específicas (NAPNEs) e, no caso do IF Sudeste MG, o Núcleo de Ações Inclusivas (NAl) estão previstos em todos os referidos IFs, apesar de identificados apenas 22 (37\%) Regulamentos e 4 (6,7\%) Regimentos de NAPNE.

O NAPNE foi proposto a partir do Programa Educação, Tecnologia e Profissionalização para Pessoas com Necessidades Específicas (TEC NEP), destinado à Rede Federal, que disponibilizou recursos financeiros, capacitando servidores e propondo a implantação dos NAPNEs em todos os IFs para atuarem como setores estratégicos para o estabelecimento da cultura inclusiva (ANJOS, 2006; NUNES, 2012; NASCIMENTO e FARIA, 2013).

Apesar do Programa ter sido vigente apenas entre os anos 2000 e 2011, foi a única experiência de organização da educação inclusiva na Rede Federal e, por isso, ainda influencia as ações dos IFs, como a implementação dos NAPNEs, que, por sua vez, ganha características particulares de funcionamento em cada IF (NASCIMENTO e FARIA, 2013; OLIVEIRA, 2017).

Em relação à TE, tema que não chegou a ser abordado no extinto Programa TEC NEP, foi possível identificar que poucos IFs a regulamentaram. Constatou-se que, até o ano de 2020, apenas 13 deles (34\%) mencionam a TE nos documentos analisados, conforme apresenta o Quadro 2. 
Quadro 2 - Previsão da TE nos documentos dos IFs

(continua)

\begin{tabular}{|c|c|c|c|}
\hline Documento que prevê a TE & IF & $\begin{array}{c}\text { A quem se destina a } \\
\text { TE }\end{array}$ & $\begin{array}{c}\text { Para qual(is) } \\
\text { modalidade(s) de curso } \\
\text { está prevista a TE }\end{array}$ \\
\hline $\begin{array}{l}\text { Manual de Orientações para } \\
\text { Adaptações / Adequações Curriculares } \\
\text { e Terminalidade Específica (IFB, 2018) }\end{array}$ & IFB & $\begin{array}{l}\text { Estudantes com grave } \\
\text { DI/DM }\end{array}$ & Não informado \\
\hline $\begin{array}{l}\text { Política de Inclusão da Pessoa com } \\
\text { Deficiência e/ou Outras Necessidades } \\
\text { Específicas (IFBA, 2017) }\end{array}$ & IFBA & $\begin{array}{l}\text { Estudantes com } \\
\text { deficiência intelectual - } \\
\text { DI }\end{array}$ & $\begin{array}{l}\text { Cursos técnicos de nível } \\
\text { médio e superior. }\end{array}$ \\
\hline Regulamento do AEE (2018a) & $\begin{array}{l}\text { IFBAIA- } \\
\text { NO }\end{array}$ & $\begin{array}{l}\text { Estudantes rom } \\
\text { deficiências graves ou } \\
\text { DM }\end{array}$ & Não informado \\
\hline $\begin{array}{l}\text { Regulamentação para o AEE (IFC, } \\
\text { 2018) }\end{array}$ & IFC & $\begin{array}{l}\text { Estudantes com } \\
\text { deficiências }\end{array}$ & Não informado \\
\hline 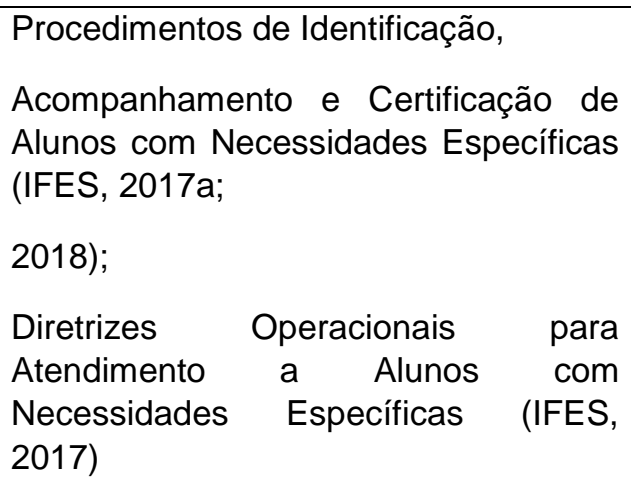 & IFES & $\begin{array}{l}\text { Estudantes com DI, } \\
\text { Transtornos Globais } \\
\text { do Desenvolvimento - } \\
\text { TGD }\end{array}$ & Não informado \\
\hline $\begin{array}{l}\text { Regulamento de Terminalidade } \\
\text { Específica (IFFAR, 2016); } \\
\text { Regulamento do AEE (IFFAR, 2019) }\end{array}$ & IFFAR & $\begin{array}{l}\text { Estudantes com grave } \\
\text { DI/DM. }\end{array}$ & $\begin{array}{l}\text { Cursos técnicos de nível } \\
\text { médio e superior. }\end{array}$ \\
\hline $\begin{array}{l}\text { Programa de Acessibilidade } \\
\text { Educacional (IFF, 2018) }\end{array}$ & IFF & $\begin{array}{l}\text { Estudantes com DI, } \\
\text { TGD }\end{array}$ & Não informado \\
\hline Regulamento NAPNE (IFG, 2018) & IFG & $\begin{array}{l}\text { Estudantes com grave } \\
\text { DI/DM. }\end{array}$ & $\begin{array}{l}\text { Cursos técnicos de nível } \\
\text { médio e superior. }\end{array}$ \\
\hline $\begin{array}{l}\text { Regulamento para a Educação } \\
\text { Inclusiva e Educação Especial } \\
\text { (IFGOIANO, 2017) }\end{array}$ & $\begin{array}{l}\text { IFGOIA } \\
\text { NO }\end{array}$ & $\begin{array}{l}\text { Estudantes com } \\
\text { deficiência, } \\
\text { Transtornos Globais } \\
\text { do Desenvolvimento, } \\
\text { transtornos } \\
\text { específicos de } \\
\text { aprendizagem, jovens, } \\
\text { adultos e idosos com } \\
\text { deficiência à educação } \\
\text { ao longo da vida }\end{array}$ & $\begin{array}{l}\text { Todos os níveis } \mathrm{e} \\
\text { modalidades }\end{array}$ \\
\hline
\end{tabular}


Quadro 2 - Previsão da TE nos documentos dos IFs

(conclusão)

\begin{tabular}{|c|c|c|c|}
\hline Documento que prevê a TE & IF & $\begin{array}{c}\text { A quem se destina a } \\
\text { TE }\end{array}$ & $\begin{array}{c}\text { Para qual(is) } \\
\text { modalidade(s) de curso } \\
\text { está prevista a TE }\end{array}$ \\
\hline $\begin{array}{l}\text { Normativa de procedimentos para } \\
\text { implantação e/ou implementação do } \\
\text { NAPNE (IFMT, 2013) }\end{array}$ & IFMT & Não informado & Não informado \\
\hline Plano de Acessibilidade (IFPB, 2015a) & IFPB & Não informado & Não informado \\
\hline $\begin{array}{l}\text { Regulamento NAPNE (IFRO, 2011); } \\
\text { Parecer Sobre a Aplicação do Instituto } \\
\text { da "Terminalidade Específica" (IFRO, } \\
\text { 2017) }\end{array}$ & IFRO & Não informado & Não informado \\
\hline $\begin{array}{l}\text { Instrução Normativa - Procedimentos } \\
\text { Relativos ao Planejamento de } \\
\text { Estratégias Educacionais a Serem } \\
\text { Dispensadas aos Estudantes com } \\
\text { Deficiência (IFSUL, 2016a) }\end{array}$ & IFSUL & $\begin{array}{c}\text { Estudantes com grave } \\
\text { DI/DM }\end{array}$ & $\begin{array}{l}\text { Cursos técnicos de nível } \\
\text { médio }\end{array}$ \\
\hline
\end{tabular}

Fonte: Autores (2020).

A maior parte (75\%) dos documentos identificados no Quadro 2 é recente, tendo sido publicada entre os anos de 2016 e 2018.

Faz sentido esse movimento recente dos IFs para planejar e organizar a TE, em virtude de que o entendimento de que ela poderia ser adotada no ensino técnico de nível médio deu-se de forma mais evidente a partir do Parecer do CNE/CBE (BRASIL, 2013).

Soma-se a esse fato, a alteração da Lei de Cotas (BRASIL, 2016a), que, a partir de 2016, condicionou os IFs a reservarem parte de suas vagas para ingresso de estudantes com deficiência, possibilitando a ampliação desse público nas instituições e requisitando a reformulação de práticas educacionais.

Os documentos de 4 IFs $(30,7 \%)$, dentre os quais estão os três mais antigos (IFRO, 2011; IFMT, 2013; IFPB, 2015; IFBA, 2017), mencionam a TE apenas como garantia legal, reproduzindo o texto da LDBEN sem explicitar uma proposta de ação.

A maior parte dos instrumentos analisados não define em quais níveis de ensino a TE pode ser aplicada, apenas $4(33,3 \%)$ indicam que seja a cursos técnicos (integrados, concomitantes ou subsequentes ao ensino médio) e a cursos de graduação, excluindo apenas a pós-graduação, que, por sua vez, costuma ser regulamentada à parte. 
Assim, infere-se que os IFs coadunam com a análise de Silva e Pavão (2019) sobre a adoção da TE no ensino superior, pois, como estratégia da EE, envolve todas as modalidades e níveis de ensino, conforme propõe a política de educação inclusiva (BRASIL, 2008a).

Alguns documentos ampliam o público da TE, considerando, para além do público definido em legislação, estudantes "que não puderem atingir o nível exigido para a conclusão do ensino fundamental, em virtude de suas deficiências" (BRASIL, 1996), ou seja, aqueles com grave DI/DM (BRASIL, 2001; 2001a), também aqueles com deficiências em geral ou deficiências graves, TGD e, até mesmo, dificuldades de aprendizagem, indo ao encontro do proposto pelo Parecer no CNE/CEB ํㅜ 5/2019 (BRASIL, 2019).

O público foco de atenção da certificação diferenciada é o seguinte: a) Deficiência física, auditiva, visual, intelectual ou múltipla (Decreto no 5296/04); b) Transtorno do espectro autista (Lei no 12.764/2012); c) Transtornos funcionais específicos da aprendizagem (dislexia, disgrafia, discalculia, dislalia, disortográfica, déficit de atenção e hiperatividade) ou outra condição que imponha alguma dificuldade de aprendizagem. (BRASIL, 2019, p. 7).

Este fato pode representar uma preocupação, já que considera a necessidade de conceder TE a um público que talvez necessitasse apenas de adaptações curriculares e/ou pedagógicas razoáveis e pouco significativas, ou seja, que não alteram substancialmente o currículo para progredirem na formação.

Conforme já observado por lacono e Mori (2004) e Lima (2009), em uma interpretação equivocada da TE, pode-se correr o risco de induzir a abreviação da formação de um maior número de estudantes público da EE, seja com relação ao tempo ou ao conteúdo.

Todos os documentos dos IFs em análise demarcam a previsão de realização de adaptações curriculares para todos os estudantes público da EE que necessitarem; e a concessão da TE tem o registro desse processo com prerrogativa.

O documento do IFB demarca essa compreensão desde o seu início: "o centro dessa discussão são as adaptações/adequações curriculares e, somente no caso dessas adaptações/adequações não serem suficientes, ocorrerá a certificação por Terminalidade Específica" (IFB, 2018, p.6).

Sobre esse aspecto, ressalta-se que a realização de adaptações curriculares razoáveis deve ser garantida a todos estudantes público da EE que necessitarem, de 
modo a atender às suas características e "garantir o seu pleno acesso ao currículo em condições de igualdade, promovendo a conquista e o exercício de sua autonomia" (BRASIL, 2015a). Mas, a realização de adaptações curriculares, apesar de constituir condição imprescindível para a ocorrência da TE, não deve estar exclusivamente relacionada a ela.

Assim sendo, para a organização da EE no ensino técnico profissional, faz-se necessário promover, entre outras condições,

flexibilizações e adaptações curriculares, que considerem o significado prático e instrumental dos conteúdos básicos, metodologias de ensino e recursos didáticos diferenciados e processos de avaliação adequados ao desenvolvimento dos alunos que apresentam necessidades educacionais especiais, em consonância com o projeto pedagógico da escola, respeitada a frequência obrigatória. (BRASIL, 2001, p. 22).

É importante, portanto, que sejam realizados planejamentos das ações e adaptações necessárias ao atendimento dos estudantes público da EE em geral, com registro, acompanhamento e avaliação das mesmas, independentemente do desdobramento em TE.

A proposta do Plano Educacional Individualizado (PEI) responde a essas demandas, na medida em que propõe o planejamento, o registro e a avaliação de ações pedagógicas para facilitação da aprendizagem do estudantes público da EE, e possibilita "promover práticas de ensino customizadas a partir das especificidades de cada aluno" (GLAT e PLETSCH, 2013, p. 20). O PEI pode ser caracterizado, basicamente, como

um registro escrito avaliativo, formulado em equipe, que busca respostas educativas mais adequadas para as necessidades educacionais especiais apresentadas em processos de escolarização de estudantes que exigem caminhos alternativos para sua aprendizagem. (MAGALHÃES, CUNHA e SILVA, 2013, p. 45).

A maioria dos IFs (69\%) registra, nos documentos em análise, a utilização do PEI ou outro instrumento de planejamento, acompanhamento e avaliação do atendimento aos estudantes público da EE, como: Plano de Desenvolvimento Individual, Plano de Ensino Especial, Plano de Ensino Adaptado e o Plano de AEE.

O AEE, por sua vez, é mencionado como prática de inclusão em 8 (61,5\%) IFs que preveem a TE. Mas apenas 5 (38,5\%) apresentam mais detalhes, por exemplo, a descrição de sua organização e a disponibilização de modelo de plano de AEE. 
Pertile e Mori (2018, p.1) destacam a importância da implementação do AEE e da TE, nos IFs, para favorecer o processo educacional e de formação dos estudantes público da EE, indicando que há necessidade de

\begin{abstract}
ampliar as discussões sobre formas de organização diferenciadas dos processos educacionais e a importância do Atendimento Educacional Especializado (AEE) no ensino profissional para a permanência dos alunos e constituição de uma formação que atenda às necessidades desses sujeitos, principalmente da indicação do uso da terminalidade específica para a certificação.
\end{abstract}

Na organização da TE, destacam-se o IFC, o IFES, o IFF, o IFFAR e o IFSul, que preveem, em seus documentos, a organização da TE de forma mais detalhada, com definição de procedimentos e apresentação de formulários modelos.

O IFC indica que a TE será definida por parecer descritivo da equipe do AEE, a partir de processo, no qual conste todos os registros previstos e padronizados do estudante (Plano de AEE, Plano de Acessibilidade ao Componente Curricular e Parecer de Desempenho no Componente Curricular), para chancela pela Pró-reitoria de Ensino (IFC, 2018).

O IFES propõe que a TE seja definida por comissão examinadora própria (instituída pela Diretoria de Ensino), a partir de todos os registros previstos e padronizados para o estudante (Registro de Atendimento Inicial, PEI, Relatório Individual para TE, Relatório do Coletivo Docentes Sobre o Discente Acompanhado) e das discussões sobre o mesmo em reuniões pedagógicas intermediárias e finais. Ademais, apresenta formulário para parecer de comissão examinadora sobre a certificação por TE e modelo de descrição de TE para registro no diploma e histórico escolar (IFES, 2017a).

O IFF, por sua vez, indica que a TE será definida por comissão examinadora própria, composta pela Diretoria de curso, Coordenação de curso, Docente do componente curricular e Equipe técnico-pedagógica, que embasará seu parecer nos registros previstos e padronizados (Plano de Ensino Adaptado e Relatório Individual de Alunos com Deficiência), realizados pelos professores em cada componente curricular (IFF, 2018).

O IFFar demarca que a TE será definida por comissão examinadora própria (instituída pela Diretoria de Ensino), que baseará seu parecer nos registros, previstos e padronizados, do processo de ensino e aprendizagem do estudante (Formulário para registro pelos professores das adaptações realizada e modelo de Parecer Pedagógico Descritivo Semestral). Além disso, apresenta modelo de parecer de banca examinadora 
http://dx.doi.org/10.5902/1984686X48006

para TE e modelo de descrição para diploma e histórico escolar em caso de TE (IFFAR, 2019).

Já o IFSul aponta que a TE será definida em colegiado pela Câmara de Ensino, a partir de um Projeto de TE, constando todos os registros, previstos e padronizados, de acompanhamento do estudante (Plano de AEE, Instrumento de Diagnóstico Escolar, Plano de Ensino Especial para cada componente curricular). É previsto também que o Projeto de TE deve ser o Projeto Pedagógico do Curso reformulado, constando todas as adaptações e flexibilizações adotadas para atender às necessidades do estudante (IFSUL, 2016a).

Os documentos do IFBaiano e o IFGoiano também organizam os procedimentos para TE, mas não apresentam os modelos padronizados.

Todos esses IFs, que organizam de forma mais detalhada a certificação por TE, preveem a emissão de diploma regular do curso, inserindo nota indicativa de TE no verso e/ou incorporando indicação no histórico escolar, no qual, em todos os casos, serão elencadas as competências desenvolvidas pelo estudante, de modo similar ao proposto no Parecer CNE/CEB no 5/2019 (BRASIL, 2019), já mencionado.

Ressalta-se, de modo especial, o IFC por ser o único a propor uma articulação com os conselhos profissionais a fim de viabilizar a atuação profissional dos estudantes certificados por TE, indicando que "a equipe de AEE deverá, nos casos de certificação por terminalidade específica, realizar articulação com os conselhos profissionais, a fim de viabilizar a atuação dos profissionais no mercado de trabalho" (IFC, 2018, p. 12). Apesar de não especificar como aconteceria tal articulação, sinaliza uma preocupação, já mencionada inicialmente, como questionamento à proposta de certificação diferenciada, desenhada no Parecer do CNE/CEB no 5/2019 (BRASIL, 2019).

Outra constatação diz respeito à definição da TE nos instrumentos selecionados dos IFs. Com exceção do IFC, nenhum outro documento examinado define a TE sem fazer referência direta ou muito próxima do texto da legislação. Fato que pode ser um indicativo da dificuldade de interpretação do significado da proposta, tendo em vista a complexidade de situações e interpretações que envolvem o estatuto da TE, conforme supracitado.

Ainda sobre a organização da TE, alguns IFs, como é o caso do IFF e do IFB, preveem a certificação intermediária como possibilidade de certificação diferenciada a depender de cada caso. 
http://dx.doi.org/10.5902/1984686X48006

Aos alunos que não puderem obter o certificado para terminalidade do curso pleiteado, devido a suas limitações, será conferido um certificado de formação intermediária, observando-se Catálogo Nacional de Cursos Técnicos (CNCT), emitido pelo MEC em junho de 2012, com edição revisada em abril de 2014 e Classificação Brasileira de Ocupações - CBO bem como os objetivos atingidos pelo aluno de forma individual, conforme normatizam a Portaria Interministerial no 5/2014, artigo 4ํ e também o Decreto no 3.298/1999, artigo 28, § 2 e 3. (IFF, 2018, p. 34).

A certificação intermediária, na Educação Profissional, está amparada no Art. 15 das Diretrizes Curriculares Nacionais para o Ensino Médio (BRASIL, 2018).

\begin{abstract}
Na organização do itinerário de formação técnica e profissional podem ser ofertados tanto a habilitação profissional técnica quanto a qualificação profissional, incluindo-se o programa de aprendizagem profissional em ambas as ofertas. [...] O itinerário formativo possibilita a concessão de certificados intermediários de qualificação profissional técnica, desde que seja estruturado e organizado em etapas com terminalidade, segundo os interesses dos estudantes, as possibilidades das instituições e redes de ensino, as demandas do mundo do trabalho e a relevância para o contexto local. (BRASIL, 2018, p. 9).
\end{abstract}

Nesse caso, o estudante não teria a certificação regular do curso sem ter as competências mínimas para exercer a profissão, de modo a evitar consequências futuras na continuidade dos estudos ou no trabalho, conforme já demarcado, e também não sairia do contexto da Educação Profissional sem nenhuma certificação, como se todo esforço empreendido no processo formativo tivesse sido em vão.

Todavia, ao considerar as falhas de compreensão da TE, já expostas na introdução desse artigo, deve-se refletir ainda sobre a existência de casos mais extremos de estudantes com graves deficiências e substantiva defasagem na aprendizagem que podem acessar cursos de formação profissional.

Nesses casos, talvez seja mais difícil certificar a conclusão de um curso de formação profissional de nível médio ou superior com o desenvolvimento das habilidades e competências mínimas previstas, ou até mesmo, conseguir certificar uma qualificação profissional intermediária dentro do respectivo curso. Sem contar as situações em que a certificação de uma etapa de escolaridade regular, como o ensino médio, pode estar condicionada à uma formação profissional, como no caso dos cursos técnicos ofertados na forma integrada ao ensino médio.

\title{
A TE na prática dos IFs
}

Quando a investigação volta-se para a prática da certificação por TE nos IFs, as evidências tornam-se menores. 
http://dx.doi.org/10.5902/1984686X48006

Dentre os 38 IFs existentes e pesquisados, apenas $6(15,8 \%)$ indicaram ter certificado algum estudante por TE, conforme apresenta o Quadro 3.

Nos últimos cinco anos (2015 a 2019), 11 discentes com deficiência foram certificados por TE nos IFs. Aparentemente, um número pequeno; no entanto, na ausência de um censo que discrimine o número de estudantes com deficiência matriculados e concluintes nos IFs, fica difícil fazer uma análise mais objetiva.

Quadro 3 - Identificação das certificações por TE concedidas pelo IFs

(continua)

\section{Certificação por Terminalidade Específica concedida(s) pelos IFs}

\begin{tabular}{|c|c|c|c|c|c|}
\hline \multicolumn{6}{|c|}{ Certificação por Terminalidade Específica concedida(s) pelos IFs } \\
\hline IF & $\begin{array}{c}\text { Quantitativo de } \\
\text { alunos certificados } \\
\text { por TE / Tipo de } \\
\text { deficiência }\end{array}$ & $\begin{array}{c}\text { Curso/modalidade } \\
\text { cursado }\end{array}$ & $\begin{array}{c}\text { Ano de } \\
\text { ingresso no } \\
\text { curso }\end{array}$ & $\begin{array}{c}\text { Ano de } \\
\text { conclusã } \\
\text { o do } \\
\text { curso }\end{array}$ & $\begin{array}{c}\text { Apresentou } \\
\text { certificado de } \\
\text { Terminalida- } \\
\text { de Específica } \\
\text { da etapa de } \\
\text { ensino } \\
\text { anterior? }\end{array}$ \\
\hline IFAP & 01/Não informou & $\begin{array}{l}\text { Técnico em logística } \\
/ \quad \text { curso técnico } \\
\text { subsequente } \\
\text { ensino médio }\end{array}$ & Não informou & $\begin{array}{l}\text { Não } \\
\text { informou }\end{array}$ & Não informou \\
\hline \multirow[t]{2}{*}{ IFES } & \multirow[t]{2}{*}{$\begin{array}{l}02 \text { / Deficiência } \\
\text { Intelectual }\end{array}$} & $\begin{array}{l}\text { Técnico em } \\
\text { Agropecuária /Curso } \\
\text { técnico integrado ao } \\
\text { ensino médio }\end{array}$ & 2012 & 2017 & Não \\
\hline & & $\begin{array}{l}\text { Técnico em } \\
\text { Zootecnia/ Curso } \\
\text { técnico integrado ao } \\
\text { ensino médio }\end{array}$ & 2014 & 2018 & Não \\
\hline \multirow[t]{3}{*}{ IF GOIANO } & \multirow[t]{2}{*}{$\begin{array}{l}02 \text { / Deficiência } \\
\text { Intelectual }\end{array}$} & $\begin{array}{l}\text { Técnico } \\
\text { Agropecuária/ Curso } \\
\text { técnico integrado ao } \\
\text { ensino médio }\end{array}$ & 2017 & 2019 & Não \\
\hline & & $\begin{array}{l}\text { Técnico em } \\
\text { informática/ Curso } \\
\text { técnico subsequente } \\
\text { ao ensino médio }\end{array}$ & 2014 & 2015 & Não \\
\hline & $\begin{array}{l}\text { 01/ Deficiência } \\
\text { Intelectual Severa }\end{array}$ & $\begin{array}{lr}\text { Tecnologia } & \text { em } \\
\text { Análise } & \text { e } \\
\text { Desenvolvimento } & \text { de } \\
\text { Sistemas/ } & \text { Curso } \\
\text { superior } & \text { de } \\
\text { tecnologia } & \end{array}$ & 2014 & 2017 & Sim \\
\hline
\end{tabular}


http://dx.doi.org/10.5902/1984686X48006

Quadro 3 - Identificação das certificações por TE concedidas pelo IFs

(conclusão)

\begin{tabular}{|c|c|c|c|c|c|}
\hline \multicolumn{6}{|c|}{ Certificação por Terminalidade Específica concedida(s) pelos IFs } \\
\hline IFMT & \multirow{3}{*}{ 03/ Deficiência física } & $\begin{array}{l}\text { Técnico } \\
\text { Agropecuária/ Curso } \\
\text { técnico subsequente } \\
\text { ao ensino médio }\end{array}$ & $2014 / 2$ & $2015 / 2$ & Sim \\
\hline & & $\begin{array}{l}\text { Técnico } \\
\text { Agropecuária/ Curso } \\
\text { técnico integrado ao } \\
\text { ensino médio }\end{array}$ & $2013 / 2$ & $2015 / 1$ & Sim \\
\hline & & $\begin{array}{lr}\text { Técnico } & \text { em } \\
\text { Alimentação } & \text { Escolar/ } \\
\text { Curso } & \text { técnico } \\
\text { subsequente } & \text { ao } \\
\text { ensino médio } & \end{array}$ & 2015 & 2017 & Não \\
\hline IFPB & 01/ Não informada & $\begin{array}{lr}\text { Técnico } & \text { em } \\
\text { informática/ Curso } \\
\text { técnico subsequente } \\
\text { ao ensino médio }\end{array}$ & Não informou & $\begin{array}{l}\text { Não } \\
\text { informou }\end{array}$ & Não informou \\
\hline IFSP & $\begin{array}{l}\text { 01/ Deficiência } \\
\text { Intelectual }\end{array}$ & $\begin{array}{lr}\text { Técnico } & \text { em } \\
\text { Mecânica/ Curso } \\
\text { técnico integrado ao } \\
\text { ensino médio EJA }\end{array}$ & Não informou & 2016 & Não \\
\hline
\end{tabular}

Fonte: Autores (2020).

Ao explorar os dados relativos às certificações por TE realizadas pelos IFs, observase que, em grande parte, elas ocorreram em cursos técnicos, na modalidade integrada ao ensino médio ou subsequente a ele, com exceção de um caso de curso superior de tecnologia e um relativo a curso técnico integrado ao ensino médio na modalidade de EJA.

A maior parte dos estudantes certificados, o que totaliza $6(54,5 \%)$ deles, possui deficiência intelectual (DI); além disso, outros 2 (18,2\%) discentes certificados não tiveram a deficiência declarada e, ainda, 3 (27,3\%) alunos possuem deficiência física.

Nota-se que a aplicação da TE não tem sido restrita ao público previsto na legislação em vigor, aos "educandos com grave deficiência mental ou múltipla" (BRASIL, 2001, p. 28). Ademais, a TE concedida aos estudantes com deficiência física não encontra amparo na legislação vigente, além de não possuir respaldo no âmbito da própria instituição, a qual não dispõe de regulamentação específica sobre TE. 
Outrossim, metade dos IFs que já certificaram estudantes por TE (IFAP, IFMT e IFSP) não possui regulamentação para tal procedimento, ou mesmo não preveem tal processo em seus documentos públicos relacionados a ações inclusivas.

Percebe-se ainda que apenas $3(27,3 \%)$, dos 11 estudantes em análise, apresentaram certificação por TE da etapa anterior de escolaridade, sendo $2 \mathrm{com}$ deficiência física e 1 com DI.

Tal fato evidencia que, na educação básica ofertada por outras redes de ensino, também não tem sido observado o público passível de TE definido na legislação. Parece, portanto, que a TE está sendo endereçada a qualquer estudante público da EE que não consiga desenvolver as habilidades e competências mínimas previstas para a etapa escolar e/ou para o qual a escola tenha dificuldade de oferecer condições acessíveis de desenvolvimento e progressão.

O único estudante identificado com DI severa obteve TE em curso superior de Tecnologia em Análise e Desenvolvimento de Sistemas, do IF Goiano. Ele já havia recebido certificação por TE na etapa anterior de ensino, o que significa que não conseguiu desenvolver as competências mínimas do ensino médio, contudo, progrediu para a etapa de ensino posterior, no caso, em curso superior.

No entanto, outro estudante, também com DI, que obteve certificação por TE, no IFSP, em curso Técnico em Mecânica integrado ao ensino médio na modalidade de EJA, não apresentou a certificação da etapa anterior ou atual de ensino por TE, podendo ser do ensino fundamental ou ensino médio regular. Todavia, tendo sido certificado no IFSP, na modalidade de EJA, pode-se extrair que, para além da ultrapassagem da faixa etária prevista para alguns níveis de ensino, o estudante não desenvolveu as competências mínimas da etapa de ensino anterior/atual e, por esse motivo, não progrediu para a etapa posterior de ensino, que poderia ser o ensino médio regular, curso técnico concomitante/subsequente ao ensino médio ou superior.

A interpretação de ambos os casos confirma a situação descrita anteriormente, de uma certa ambivalência da TE. Ora representando a conclusão de uma etapa ensino, conforme exprimem alguns aparatos legais (BRASIL, 1996; 2001; 2001a), ora representando a certificação da escolaridade desenvolvida na etapa de ensino, conforme circunscrevem as interpretações mencionadas da SEESP/MEC (BRASIL 2009a, 2009b, 2009c apud BRASIL, 2015). 


\section{Considerações finais}

O presente estudo evidenciou que a política educacional tem viabilizado interpretações dúbias sobre o estatuto da TE, o que pode influenciar as práticas escolares e, inclusive, vir a descaracterizar a proposta de educação inclusiva, na medida em que possibilita o entendimento da TE como uma prática discriminatória de estudantes por motivo de deficiência e como uma prática impeditiva para realização de aprendizagens ao longo da vida. No que concerne à adoção da TE no âmbito dos IFs, foi possível constatar que a regulamentação e implementação da TE ainda é uma realidade pouco expressiva e eficaz. Apenas $13 \mathrm{IFs}$ (34\%) preveem este estatuto em seus documentos e somente 6 $(15,8 \%)$ certificaram estudantes por TE.

O conteúdo dos materiais analisados evidenciou interpretações subjetivas e diferenciadas sobre a adoção da TE, seja com relação à sua organização, prevendo ou não a certificação intermediária e a preocupação com a inserção profissional do estudante certificado por TE, seja com relação ao público a que se destina.

Foi possível constatar que os IFs têm assumido a TE para a conclusão de uma etapa formativa profissional, certificando regularmente, de acordo com o previsto para cada curso, e declarando apenas as habilidades e competências desenvolvidas, na perspectiva de uma atuação profissional possível, mostrando à sociedade a incompletude da formação técnica profissional.

Todavia, reconhecendo as limitações desse estudo, que não possibilitou uma análise mais aprofundada dos casos de certificação por TE em cada IF, reforça-se a necessidade de realização de mais estudos e discussões sobre a TE, tendo como suporte a Declaração de Incheon (UNESCO, 2015) e a LBI (BRASIL,2015a), as quais preveem "educação ao longo da vida" para o público da EE. Inclusive há necessidade de discussão sobre a TE no contexto da educação básica, a qual incumbe orientar e direcionar os estudantes com DI/DM para processos de socialização, escolarização, profissionalização e/ou empregabilidade futuros, uma vez que esse público, apesar das previsões da Convenção (BRASIL, 2007; 2008; 2009), ainda carece de normativas objetivas que garantam sua participação efetiva na sociedade. 


\section{Referências}

ANJOS, Isa Regina Santos dos. Programa TEC NEP: avaliação de uma proposta de educação profissional inclusiva. 2006. Dissertação (Mestrado em Educação Especial) Centro de Educação e Ciências Humanas, Universidade Federal de São Carlos, São Paulo, 2006. Disponível em: https://repositorio.ufscar.br/handle/ufscar/2949?show=full Acesso em: 08 dez. 2019.

BARDIN, Laurence. Análise de Conteúdo. Lisboa: Editora Setenta, 1977.

BRASIL. Lei no 9.394, de 20 de dezembro de 1996. Lei de Diretrizes e Bases da Educação Nacional. Brasília, DF, 1996.

BRASIL. Ministério da Educação. Parecer CNE/CBE no 17/2001. Diretrizes Nacionais para a Educação Especial na Educação Básica. Brasília, DF, 2001, 32p.

BRASIL. Ministério da Educação. Resolução CNE/CBE no. 2/2001. Institui Diretrizes Nacionais para a Educação Especial na Educação Básica. Brasília, DF, 2001a, 5p.

BRASIL. Presidência da República. Secretaria Especial dos Direitos Humanos. Coordenadoria Nacional para Integração da Pessoa Portadora de Deficiência. Convenção sobre os Direitos das Pessoas com Deficiência: Protocolo Facultativo à Convenção sobre os Direitos das Pessoas com Deficiência. Tradução Oficial/Brasil. Brasília, DF, 2007, 48p.

BRASIL. Decreto Legislativo no 186, 9 de junho de 2008. Aprova o texto da Convenção sobre os Direitos das Pessoas com Deficiência e de seu Protocolo Facultativo, assinados em Nova lorque, em 30 de março de 2007. Brasília, DF, 2008.

BRASIL. Ministério da Educação. Política Nacional da Educação Especial na Perspectiva da Educação Inclusiva. Brasília, DF, 2008a.

BRASIL. Decreto n 6.949, de 25 de agosto de 2009. Promulga a Convenção Internacional sobre os Direitos das Pessoas com Deficiência e seu Protocolo Facultativo, assinados em Nova York, em 30 de março de 2007. Brasília, DF, 2009.

BRASIL. Lei no 12.527, de 18 de novembro de 2011. Regula o acesso a informações previsto na Constituição Federal; altera a Lei no 8.112, de 11 de dezembro de 1990; revoga a Lei no 11.111, de 5 de maio de 2005, e dispositivos da Lei no 8.159, de 8 de janeiro de 1991; e dá outras providências. Brasília, DF, 2011.

BRASIL. Lei no 12.711, de 29 de agosto de 2012. Dispõe sobre o ingresso nas universidades federais e nas instituições federais de ensino técnico de nível médio e dá outras providências. Brasília, DF, 2012.

BRASIL. Ministério da Educação. Parecer CNE n² 2/2013. Consulta sobre a possibilidade de aplicação de "terminalidade especifica" nos cursos técnicos integrados ao Ensino Médio. Brasília, DF, 2013, 5p. 
BRASIL. Ministério da Educação. Catálogo Nacional de Cursos Técnicos. Brasília, DF, 2014, 290p. 3ํㅡㄹ ed. Disponível em:

http://portal.mec.gov.br/index.php?option=com_docman\&view=download\&alias=77451-cnct3a-edicao-pdf-1\&category_slug=novembro-2017-pdf\&ltemid=30192 Acesso em: 6 abr. 2020.

BRASIL. Ministério da Educação. Secretaria de Educação Continuada, Alfabetização, Diversidade e Inclusão. Orientações para implementação da política de educação especial na perspectiva da educação inclusiva. Brasília, DF, 2015, 200p. Disponível em: http://portal.mec.gov.br/index.php?

option=com_docman\&view=download\&alias=17237-secadi-documento-subsidiario2015\&Itemid=30192 Acesso em: 10 jan. 2020.

BRASIL. Lei №. 13.146, de 6 de julho de 2015. Institui a Lei Brasileira de Inclusão das Pessoas com Deficiência (Estatuto da Pessoa com Deficiência). Brasília, DF, 2015a.

\section{BRASIL. Ministério da Educação. Catálogo Nacional de Cursos Superiores de}

Tecnologia. Brasília, DF, 2016, 194p. 3를 ed. Disponível em:

http://portal.mec.gov.br/index.php?option=com_docman\&view=download\&alias=98211 cncst-2016-a\&category_slug=outubro-2018-pdf-1\&ltemid=30192 Acesso em: 6 abr. 2020.

BRASIL. Lei $\mathrm{n}$ - 13.409, de 28 de dezembro de 2016. Altera a Lei $\mathrm{n}$ - 12.711, de 29 de agosto de 2012, para dispor sobre a reserva de vagas para pessoas com deficiência nos cursos técnico de nível médio e superior das instituições federais de ensino. Brasília, DF, 2016a.

BRASIL. Ministério da Educação. Resolução CNE/CBE n 3/2018. Atualiza as Diretrizes Curriculares Nacionais para o Ensino Médio. Brasília, DF, 2018, 16p.

BRASIL. Ministério da Educação. Parecer CNE/CBE no. 5/2019. Consulta acerca do desenvolvimento do Plano Educacional Individualizado (PEI) de estudantes com necessidades educacionais específicas, visando desenvolver uma política de aplicação do procedimento de certificação diferenciada e assegurar o direito à terminalidade específica aos educandos. Brasília, DF, 2019, 8p. Disponível em:

http://portal.mec.gov.br/index.php?option=com_docman\&view=download\&alias=118421 pceb005-19\&category_slug=julho-2019-pdf\&Itemid=30192 Acesso em: 8 fev. 2020.

BRASIL. Ministério da Educação. Plataforma Nilo Peçanha. Brasília, DF, 2019a. Disponível em: http://plataformanilopecanha.mec.gov.br/2019.html Acesso em: 29 jan. 2020.

BRASIL. Ministério do Trabalho. Classificação Brasileira de Ocupações - CBO. Brasília, DF, 2020. Disponível em: http://www.mtecbo.gov.br/ cbosite/pages/home.jsf Acesso em: 08 mai. 2020.

ELIAS, Claudia de Souza Rodrigues. et al. Quando chega o fim? Uma revisão narrativa sobre terminalidade do período escolar para alunos deficientes mentais. Revista Eletrônica Saúde Mental Álcool e Drogas. São Paulo, n. 01, v. 08, jan/abr 2012. Disponível em: http://www.revistas.usp.br/ smad/article/view/49594/53669. Acesso em: 03 nov. 2019. 
http://dx.doi.org/10.5902/1984686X48006

FLICK, Uwe. Introdução à pesquisa qualitativa. 3 ed. Porto Alegre: Artmed, 2009.

GIL, Antonio Carlos. Como elaborar projetos de pesquisa. 4. ed. São Paulo: Atlas, 2002.

GLAT, Rosana; PLETSCH, Denise. Plano Educacional Individualizado (PEI): um diálogo entre práticas curriculares e processos de avaliação escolar. In: GLAT, Rosana;

PLETSCH, Denise (Orgs.). Estratégias educacionais diferenciadas para alunos com necessidades especiais. Rio de Janeiro: EdUERJ, 2013. p. 17-32.

IACONO, Jane Peruzo; MORI, Nerli Nonato Ribeiro. Deficiência mental e terminalidade específica: novas possibilidades de inclusão ou exclusão velada? In: Anped Sul Seminário de Pesquisa em Educação da Região Sul, 5. Curitiba, 2004. Anais. Curitiba: Editora Universitária Champagnat, v.1. 2004. Disponível em:

https://www.unioeste.br/portal/arquivos/proex/pee/nov_pos_de_incl_ou_excl_vel.pdf. Acesso em: 03 nov. 2019.

INSTITUTO FEDERAL DE EDUCAÇÃO, CIÊNCIA E TECNOLOGIA DO ACRE (IFAC). Resolução no. 145, de 12 de julho de 2013. Regulamenta a organização, o funcionamento e as atribuições do Núcleo de Atendimento às Pessoas com Necessidades Específicas - NAPNE do IFAC. Rio Branco, AC, 2013. 9p. Disponível em: http://www.ifac.edu.br/index.php? option=com docman\&task=doc_details\&gid=1752\&Itemid=120. Acesso em: 11 jan. 2020.

INSTITUTO FEDERAL DE EDUCAÇÃO, CIÊNCIA E TECNOLOGIA DE ALAGOAS (IFAL). Resolução № 45, de 22 de dezembro de 2014. Dispõe sobre a organização, o funcionamento e as atribuições do Núcleo de Atendimento às Pessoas com Necessidades Específicas - NAPNE do IFAL. Maceió, AL, 2014. 9p. Disponível em: https://www2.ifal.edu.br/o-ifal/ institucional/orgaos-colegiados/conselhosuperior/arquivos/res-no-45-cs-2014-aprova-a-regulamentacao-do-napne-ifal.pdf. Acesso em: 11 jan. 2020.

\section{INSTITUTO FEDERAL DE EDUCAÇÃO, CIÊNCIA E TECNOLOGIA DE ALAGOAS} (IFAL). Resolução no 17, de 11 de junho de 2019. Aprova regulamentação de procedimentos de identificação, acompanhamento e avaliação de discentes com necessidades específicas do IFAL. Maceió, AL, 2019. 26p. Disponível em: https://www2.ifal.edu.br/o-ifal/ensino/legislacao-e-normas/arquivos-legislacao/direcao-depoliticas-estudantis/resolucao-no-17-cs-2019-identificacao-acompanhamento-e-avaliacaode-discentes-com-necessidades-esperiais-procedimentos.pdf. Acesso em: 11 jan. 2020.

\section{INSTITUTO FEDERAL DE EDUCAÇÃO, CIÊNCIA E TECNOLOGIA DO AMAZONAS} (IFAM). Resolução no. 45, de 13 de julho de 2015. Aprova as normas que trata do Regimento Interno do Núcleo de Atendimento a Pessoas com Necessidades Educacionais Especiais - NAPNE do IFAM. Manaus, AM, 2015. 6p. Disponível em: http://www2.ifam.edu.br/pro-reitorias/ extensao/ proex/formularios-e-documentos. Acesso em: 11 jan. 2020. 
INSTITUTO FEDERAL DE EDUCAÇÃO, CIÊNCIA E TECNOLOGIA DO AMAZONAS (IFAM). Resolução no. 31, de 06 de junho de 2018. Aprova o Regulamento do Procedimento para Atendimento de Alunos com Deficiência no IFAM. Manaus, AM, 2018. 11p. Disponível em: http://www2.ifam.edu.br/pro-reitorias/extensao/proex/formularios-edocumentos. Acesso em: 11 jan. 2020.

INSTITUTO FEDERAL DE EDUCAÇÃO, CIÊNCIA E TECNOLOGIA DE BRASÍLIA (IFB). Resolução n.o 024, de 16 de outubro de 2013. Institui o Regulamento do NAPNENúcleo de Atendimento às Pessoas com Necessidades Específicas. Brasília, DF, 2013, 7p. Disponível em: https://www.ifb.edu.br/attachments/5694_024_Regulamento\%20Napne.pdf. Acesso em: 11 jan. 2020.

INSTITUTO FEDERAL DE EDUCAÇÃO, CIÊNCIA E TECNOLOGIA DE BRASÍLIA (IFB). Manual de Orientações para Adaptações / Adequações Curriculares e Terminalidade Específica. Brasília, DF, 2018. 61p.

INSTITUTO FEDERAL DE EDUCAÇÃO, CIÊNCIA E TECNOLOGIA DA BAHIA. Resolução no 09, de 28 de março de 2016. Diretrizes para a Acessibilidade Pedagógica dos Estudantes com Necessidades Específicas no âmbito do IFBA. Salvador, BA, 2016. 8p. Disponível em: https://portal.ifba.edu.br/eunapolis/ assistencia-estudantil-pasta/resol09-2016-acessibilidade-pedagogica.pdf. Acesso em: 11 jan. 2020.

INSTITUTO FEDERAL DE EDUCAÇÃO, CIÊNCIA E TECNOLOGIA DA BAHIA (IFBA). Resolução no 30, de 12 de dezembro de 2017. Aprova a Política de inclusão da pessoa com deficiência e/ou outras necessidades específicas no âmbito do IFBA. Salvador, BA, 2017. 16p. Disponível em:

https://portal.ifba.edu.br/jacobina/institucional/documentos/resolucao-30-2017-politicainclusao-pessoa-com.pdf/view. Acesso em: 11 jan. 2020.

INSTITUTO FEDERAL DE EDUCAÇÃO, CIÊNCIA E TECNOLOGIA DA BAHIA (IFBA). Cartilha práticas acadêmicas inclusivas. Salvador, BA, 2019. 36p. Disponível em: https://portal.ifba.edu.br/proen/departamentos/permanencia-assistenciaestudantil/praticas-academicas-inclusivas-visualizacao-digital.pdf. Acesso em: 12 jan. 2020.

INSTITUTO FEDERAL DE EDUCAÇÃO, CIÊNCIA E TECNOLOGIA DA BAHIA (IFBA). Cartilha Orientação para atendimento a pessoas com deficiência. Salvador, BA, s/d, 15p. Disponível em: https://portal.ifba.edu.br/proen/ departamentos/permanenciaassistencia-estudanti//orientacao-para-atendimento-pessoas-com-deficiencia. Acesso em: 12 jan. 2020.

INSTITUTO FEDERAL DE EDUCAÇÃO, CIÊNCIA E TECNOLOGIA BAIANO (IFBAIANO). Regimento do Núcleo de Atendimento às Pessoas com Necessidades Específicas do IF Baiano. Salvador, BA, 2018. 12p. Disponível em:https://ifbaiano.edu.br/portal/ensino/wpcontent/uploads/sites/2/2019/05/Regimento-doN\%C3\%BAcleo-de-Atendimento-\%C3\%A0sPessoascom NecessidadesEspec\%C3\%ADficas-do-IF-Baiano.pdf. Acesso em: 12 jan. 2020. 
INSTITUTO FEDERAL DE EDUCAÇÃO, CIÊNCIA E TECNOLOGIA BAIANO (IFBAIANO). Política da Diversidade e Inclusão do IF Baiano. Salvador, BA, 2012. 27p. Disponível em: https://ifbaiano.edu.br/portal/gestao-ti-lapa/wpcontent/uploads/sites/91/2020/02/POLITICA_DE_DIVERSIDADE_E_INCLUSAO_DO_IF_ BAIANO.pdf. Acesso em: 12 jan. 2020.

INSTITUTO FEDERAL DE EDUCAÇÃO, CIÊNCIA E TECNOLOGIA BAIANO (IFBAIANO). Regulamento do Atendimento Educacional Especializado (AEE) no âmbito do Instituto Federal de Educação, Ciência e Tecnologia Baiano. Salvador, BA, 2018. 20p. Disponível em:

https://ifbaiano.edu.br/portal/ensino/wpcontent/uploads/sites/2/2019/05/Regulamento-doAtendimento-Educacional-Especializado-no-\%C3\%A2mbito-do-IF-Baiano.pdf. Acesso em: 12 jan. 2020.

INSTITUTO FEDERAL DE EDUCAÇÃO, CIÊNCIA E TECNOLOGIA CATARINENSE (IFC). Portaria Normativa $n^{\circ}$ 04, de 29 de janeiro de 2018. Instituir a regulamentação para o Atendimento Educacional Especializado do Instituto Federal Catarinense. Blumenau, SC, 2018. 30p. Disponível em: http://ifc.edu.br/wpcontent/uploads/2018/02/Portaria-Normativa-004-2018 Regulamento-de-AtendimentoEducacional-Especializado-do-IFC.pdf. Acesso em: 14 jan. 2020.

INSTITUTO FEDERAL DE EDUCAÇÃO, CIÊNCIA E TECNOLOGIA CATARINENSE (IFC). Política de Inclusão e Diversidade do Instituto Federal Catarinense. Blumenau, SC, 2019. 13p. Disponível em:

http://consuper.ifc.edu.br/wpcontent/uploads/sites/14/2019/01/Resoluo_33.2019_ANEXO. pdf. Acesso em: 14 jan. 2020.

INSTITUTO FEDERAL DE EDUCAÇÃO, CIÊNCIA E TECNOLOGIA DO CEARÁ (IFCE). Nota Técnica nº. 001/2015/PROEXT/PROEN/IFCE. Orientação quanto à elaboração e utilização de recursos didáticos e pedagógicos adaptados aos estudantes com deficiência. Fortaleza, CE, 2015. 5p. Disponível em: https://ifce.edu.br/proext/arquivos/notatecnica_2015_elaboracao-e-utilizacao-de-materiais-adaptados.pdf. Acesso em: Acesso em: 14 jan. $20 \overline{2} 0$.

INSTITUTO FEDERAL DE EDUCAÇÃO, CIÊNCIA E TECNOLOGIA DO CEARÁ (IFCE). Resolução no 050, de 14 de dezembro de 2015. Aprova o Regulamento do NAPNEs do IFCE. Fortaleza, CE, 2015a. 5p. Disponível em:

https://ifce.edu.br/proext/arquivos/resolucao-no-050-14-de-dezembro-de-2015napnes.pdf/view. Acesso em: 14 jan. 2020.

INSTITUTO FEDERAL DE EDUCAÇÃO, CIÊNCIA E TECNOLOGIA DO CEARÁ (IFCE). Resolução no 064, de 28 de maio de 2018. Aprova a alteração da Resolução no. 050 de 15, de dezembro de 2015. Fortaleza, CE, 2018. 2p. Disponível em:

https://ifce.edu.br/proext/acessibilidade/arquivos/ resolucao-no-064-2018-altera-oregimento-napne.pdf. Acesso em: 14 jan. 2020. 
INSTITUTO FEDERAL DE EDUCAÇÃO, CIÊNCIA E TECNOLOGIA DO ESPÍRITO SANTO (IFES). Regulamento Interno NAPNE. Vitória, ES, 2014. 7p. Disponível em: https://ifes.edu.br/images/stories/files/ Pro_reitoria_ensino/fonapne/portaria_10632014_anexo_I.pdf. Acesso em: 14 jan. 2020.

\section{INSTITUTO FEDERAL DE EDUCAÇÃO, CIÊNCIA E TECNOLOGIA DO ESPÍRITO} SANTO (IFES). Resolução do Conselho Superior no 34 de 9, de outubro de 2017. Institui as Diretrizes Operacionais para Atendimento a Alunos com Necessidades Específicas no IFES. Vitória, ES, 2017. 5p. Disponível em: https://ifes.edu.br/conselhoscomissoes/conselho-superior? start=10. Acesso em: 14 jan. 2020.

\section{INSTITUTO FEDERAL DE EDUCAÇÃO, CIÊNCIA E TECNOLOGIA DO ESPÍRITO} SANTO (IFES). Resolução do Conselho Superior no 55 de 19, de dezembro de 2017. Institui Procedimentos de Identificação, Acompanhamento e Certificação de Alunos com Necessidades Específicas no IFES. Vitória, ES, 2017a. 5p. Disponível em: https://ifes.edu.br/images/stories/-publicacoes/ conselhos-comissoes/conselhosuperior/2017/Res_CS_55_2017_-_Institui procedimentos_de_identifica\%C3\%A7\%C3\%A3o_acompanhamento_e_certifica\%C3\%A 7\%C3\%A3o de alunos com Necessidades Espec\%C3\%ADficas _Alterada_Res_19_2018.pdf. Acesso em: 14 jan. 2020.

INSTITUTO FEDERAL DE EDUCAÇÃO, CIÊNCIA E TECNOLOGIA DO ESPÍRITO SANTO (IFES). Resolução do Conselho Superior no 19 de 13, de julho de 2018. Altera a Resolução no. 55/2017 de 19/12/2017 que Institui Procedimentos de Identificação, Acompanhamento e Certificação de Alunos com Necessidades Específicas no IFES. Vitória, ES, 2018. 1p. Disponível em: https://ifes.edu.br/images/stories/publicacoes/conselhos-comissoes/conselhosuperior/2018/Res_CS_19_2018_Altera_Resolu\%C3\%A7\%C3\%A30_55_2017_Institui procedimentos de identifica\%C3\%A7\%C3\%A3o acompanhamento e certifica\% $\overline{\mathrm{C}} 3 \% \mathrm{~A} 7$ $\%$ C3\%A3o_de_alunos_com_Necessidades_Espec\%C3\%ADficas.pdf Acesso em: 14 jan. 2020.

INSTITUTO FEDERAL DE EDUCAÇÃO, CIÊNCIA E TECNOLOGIA FARROUPILHA (IFFAR). Resolução CONSUP n․ 060 de 31, de agosto de 2016. Aprova o Regulamento de Terminalidade Específica do IFFAR. Santa Maria, RS, 2016. 9p. Disponível em: https://www.iffarroupilha.edu.br/regulamentoselegisla\%C3\%A7\%C3\%B5es/resolu\%C3\%A 7\%C3\%B5es/item/3064resolu\%C3\%A7\%C3\%A3o-do-consup-n\%C2\%BA-60-2016regulamento-de-terminalidade-espec\%C3\%ADfica. Acesso em: 17 jan. 2020.

INSTITUTO FEDERAL DE EDUCAÇÃO, CIÊNCIA E TECNOLOGIA FARROUPILHA (IFFAR). Resolução CONSUP no. 079 de 13, de dezembro de 2018. Aprova a Política de Diversidade e Inclusão do IFFAR. Santa Maria, RS, 2018. 16p. Disponível em: https://www.iffarroupilha.edu.br/regulamentos elegisla\%C3\%A7\%C3\%B5es/resolu\%C3\%A7\%C3\%B5es/item $/ 14719$ resolu\%C3\%A7\%C3 $\%$ A3o-consup-n\%C2\%BA-079-2018-aprova-a-pol\%C3\%ADtica-de-diversidade-einclus\%C3\%A3o-do-iffar. Acesso em: 17 jan. 2020. 
INSTITUTO FEDERAL DE EDUCAÇÃO, CIÊNCIA E TECNOLOGIA FARROUPILHA (IFFAR). Resolução CONSUP n‥ 0052 de 24, de outubro de 2019. Aprova a atualização do Regulamento do Atendimento Educacional Especializado no IFFAR. Santa Maria, RS, 2019. 16p. Disponível em: https://www.iffarroupilha.edu.br/regulamentoselegisla\%C3\%A7\% C3\%B5es/ resolu\%C3\%A7\%C3\%B5es/item/15642resolu\%C3\%A7\%C3\%A3o-consup n\%C2\%BA052-2019-atualiza\%C3\%A7\%C3\%A3o-do-regulamento-do atendimento-educacionalespecializado-no-iffar. Acesso em: 17 jan. 2020.

INSTITUTO FEDERAL DE EDUCAÇÃO, CIÊNCIA E TECNOLOGIA FLUMINENSE (IFF). Resolução no 33, de 15 de outubro de 2018. Aprova o Programa de Acessibilidade Educacional do IFF. Campos dos Goytacazes, RJ, 2018. 64p.

INSTITUTO FEDERAL DE EDUCAÇÃO, CIÊNCIA E TECNOLOGIA GOIÁS (IFG). Resolução CONSUP no 01, de 04 de janeiro de 2018. Retificar a Resolução CONSUP/IFG no 30, de 02 de outubro de 2017, que aprovou o Regulamento dos Núcleos de Atendimento às Pessoas com Necessidades Específicas - NAPNE do IFG. Goiânia, GO, 2018. 17p. Disponível em:

https://www.ifg.edu.br/attachments/article/209/Resolu\%C3\%A7\%C3\%A30\%201.pdf. Acesso em: 17 jan. 2020.

INSTITUTO FEDERAL DE EDUCAÇÃO, CIÊNCIA E TECNOLOGIA GOIANO (IFGOIANO). Resolução no 24, de 01 de março de 2013. Aprova o Regulamento Institucional do Núcleo de Atendimento às Pessoas com Necessidades Específicas NAPNE. Goiânia, GO, 2013. 6p. Disponível em:

https://www.ifgoiano.edu.br/home/images/CMPCBE/Doc_Ensino/RegulamentoInstitucional-dos-Ncleos-de-Atendimento-s-Pessoas-com-Necessidades EducacionaisEspecficas_NAPNE_Res-24_2013.pdf. Acesso em: 17 jan. 2020.

INSTITUTO FEDERAL DE EDUCAÇÃO, CIÊNCIA E TECNOLOGIA GOIANO (IFGOIANO). Resolução no 30, de 17 de junho de 2016. Aprova o Regulamento do Atendimento Educacional Especializado. Goiânia, GO, 2016. 8p. Disponível em: https://suap.ifgoiano.edu.br/media/documentos/arquivos/Regulamento_do_Atendimento_E ducacional_Especializado_AEE.pdf. Acesso em: 17 jan. 2020.

INSTITUTO FEDERAL DE EDUCAÇÃO, CIÊNCIA E TECNOLOGIA GOIANO (IFGOIANO). Resolução no 19, de 02 de maio de 2017. Aprova o Regulamento para a Educação Inclusiva e Educação Especial no âmbito do IF Goiano. Goiânia, GO, 2017. 20p. Disponível em: https://suap.ifgoiano.edu.br/media/documentos/arquivos/Regulamento_Educa\%C3\%A7\%C3\% A3o_Inclusiva_e_Especial.pdf. Acesso em: 17 jan. 2020.

INSTITUTO FEDERAL DE EDUCAÇÃO, CIÊNCIA E TECNOLOGIA DO MARANHÃO (IFMA). Resolução no. 15, de 27 de fevereiro de 2015. Dispõe sobre a Regulamentação dos procedimentos para o funcionamento do Núcleo de Atendimento às Pessoas com Necessidades Específicas - NAPNE do IFMA. São Luís, MA, 2015. 6p. Disponível em: https://proen.ifma.edu.br/wp-content/uploads/sites/32/2015/12/11032015-170842ResolucaoN15 Regulamentacao_do_Nucleo_de_Atendimento_as_Pessoas_com_Necessidades_Especifica s.pdf . Acesso em: 17 jan. $20 \overline{20}$. 
INSTITUTO FEDERAL DE EDUCAÇÃO, CIÊNCIA E TECNOLOGIA DE MINAS GERAIS (IFMG). Resolução no. 22, de 03 de novembro de 2016. Dispõe sobre a

regulamentação, funcionamento e atribuições do Núcleo de Atendimento às Pessoas com Necessidades Educacionais Específicas - NAPNEE. Belo Horizonte, MG, 2016. 11p. Disponível em: https://www2.ifmg.edu.br/portal/acesso-ainformacao/conselhosuperior/ resolucoes/2016/resolucao-022-2016-regulamento-do-napnee-final.docx. Acesso em: 17 jan. 2020.

INSTITUTO FEDERAL DE EDUCAÇÃO, CIÊNCIA E TECNOLOGIA DE MINAS GERAIS (IFMG). Instrução Normativa no. 7, de 27 de maio de 2019. Normatiza o Programa de Atendimento Educacional Especializado (PAEE) no âmbito do IFMG. Belo Horizonte, MG, 2019. 8p. Disponível em:

https://formiga.ifmg.edu.br/documents/2019/DE/InstrucoesNormativas/Instruo_Normativa_ 07-2019-_Programa_de_Atendimento_Especializado_PAEE.pdf. Acesso em: 17 jan. 2020.

INSTITUTO FEDERAL DE EDUCAÇÃO, CIÊNCIA E TECNOLOGIA DE MATO GROSSO DO SUL (IFMS). Regulamento Núcleo de Atendimento às Pessoas com

Necessidades Específicas - NAPNE. Campo Grande, MG, 2016. 17p. Disponível em: https://www.ifms.edu.br/centrais-de-conteudo/documentos-

institucionais/regulamentos/regulamento-do-nucleo-necessidades-especificas-resolucao026-de-15-04-2016.pdf. Acesso em: 18 jan. 2020.

INSTITUTO FEDERAL DE EDUCAÇÃO, CIÊNCIA E TECNOLOGIA DE MATO GROSSO (IFMT). Instrução Normativa que Orienta quanto aos procedimentos para implantação e/ou implementação do Núcleo de Atendimento às Pessoas com Necessidades Específicas - NAPNE nos Campi do IFMT. Cuiabá, MT, 2013. 8p. Disponível em: http://ifmt.edu.br/media/filer_public/88/84/88843258-9885-46a1-986784381449e5e3/7-anexo-da-resolucao-no-0432013-instrucao-normativa-do-napne.pdf. Acesso em: 18 jan. 2020.

INSTITUTO FEDERAL DE EDUCAÇÃO, CIÊNCIA E TECNOLOGIA DO NORTE DE MINAS (IFNMG). Regulamento do Núcleo de Atendimento às Pessoas com Necessidades Específicas - NAPNE. Montes Claros, MG 2014. 9p. Disponível em: https://www.ifnmg.edu.br/regulamentos-ensino. Acesso em: 18 jan. 2020.

INSTITUTO FEDERAL DE EDUCAÇÃO, CIÊNCIA E TECNOLOGIA DO NORTE DE MINAS (IFNMG). Regulamento do Núcleo de Atendimento às Pessoas com Necessidades Específicas - NAPNE. Montes Claros, MG 2019. 11p. Disponível em: https://www.ifnmg.edu.br/napneifnmg. Acesso em: 18 jan. 2020.

INSTITUTO FEDERAL DE EDUCAÇÃO, CIÊNCIA E TECNOLOGIA DO PARÁ (IFPA). Resolução no. 064/2018-CONSUP de 22, de março de 2018. Propõe as diretrizes, princípios, composição e atribuições do Núcleo de Atendimento às Pessoas com Necessidades Específicas - NAPNE do IFPA. Belém, PA, 2018. 5p. Disponível em: http://braganca.ifpa.edu.br/documentos/ campus braganca2018/napne2018/1482resolucao-n-064-2018-consup-ifpa/file. Acesso em: 20 jan. 2020. 
INSTITUTO FEDERAL DE EDUCAÇÃO, CIÊNCIA E TECNOLOGIA DA PARAÍBA (IFPB). Resolução n. 139 de 02, de outubro de 2015. Dispõe sobre o Regulamento dos Núcleos de Atendimento às Pessoas com Necessidades Específicas - NAPNEs do IFPB. João Pessoa, PB, 2015. 7p. Disponível em: https://www.ifpb.edu.br/orgaoscolegiados/ consuper/ resolucoes/2015/resolucao-no-139. Acesso em: 20 jan. 2020.

INSTITUTO FEDERAL DE EDUCAÇÃO, CIÊNCIA E TECNOLOGIA DA PARAÍBA (IFPB). Resolução no. 240 de 17, de dezembro de 2015. Dispõe sobre a aprovação do Plano de Acessibilidade do IFPB. João Pessoa, PB, 2015a. 23p. Disponível em: https://www.ifpb.edu.br/ orgaoscolegiados/ consuper/resolucoes/2015/resolucao-no240/view. Acesso em: 20 jan. 2020.

INSTITUTO FEDERAL DE EDUCAÇÃO, CIÊNCIA E TECNOLOGIA DE PERNANBUCO (IFPE). Orientações das Ações Inclusivas no IFPE. Recife, PE, 2014. 3p. Disponível em: https://portal.ifpe.edu.br/campus/ paulista/ extensao/orientacao-das-acoes-deinclusao-revisado.pdf. Acesso em: 18 jan. 2020.

INSTITUTO FEDERAL DE EDUCAÇÃO, CIÊNCIA E TECNOLOGIA DE PERNANBUCO (IFPE). Resolução no. 10/2016. Aprova as alterações no Regulamento dos Núcleos de Apoio às Pessoas com Deficiência - NAPNE do IFPE. Recife, PE, 2016. 6p. Disponível em: https://portal.ifpe.edu.br/ campus/caruaru/extensao/napne/regulamento-napne.pdf. Acesso em: 18 jan. 2020.

INSTITUTO FEDERAL DE EDUCAÇÃO, CIÊNCIA E TECNOLOGIA DO PIAUÍ (IFPI). Resolução no. 004/2015 - Conselho Superior. Aprova a Política de Diversidade e Inclusão para o IFPI. Teresina, PI, 2015. 11p. Disponível em: https://www.ifpi.edu.br/ainstituicao/proreitorias/extensao/rei_proex_regulamentopoliticadiversidadeinclusao.pdf. Acesso em: 18 jan. 2020.

INSTITUTO FEDERAL DE EDUCAÇÃO, CIÊNCIA E TECNOLOGIA DO PIAUÍ (IFPI). Resolução n. 035/2014 - Conselho Superior. Aprova Regulamento do Núcleo de Atendimento às Pessoas com Necessidades Específicas - NAPNE. Teresina, PI, 2014. 7p. Disponível em: https://www.ifpi.edu.br/a-instituicao/proreitorias/extensao/rei_proex_regulamentonapne.pdf. Acesso em: 18 jan. 2020.

INSTITUTO FEDERAL DE EDUCAÇÃO, CIÊNCIA E TECNOLOGIA DO PIAUÍ (IFPI). Resolução no. 024/2015 - Conselho Superior. Altera a Resolução nํ. 35/2014, do Regulamento do Núcleo de Atendimento às Pessoas com Necessidades Específicas NAPNE. Teresina, PI, 2015a. 3p. Disponível em: https://www.ifpi.edu.br/ainstituicao/proreitorias/extensao/rei_proex_altera regulamentonapne.pdf. Acesso em: 18 jan. 2020.

INSTITUTO FEDERAL DE EDUCAÇÃO, CIÊNCIA E TECNOLOGIA DO RIO DE JANEIRO (IFRJ). Resolução no. 55 de 17, de dezembro de 2014. Aprova 0 Regulamento do Núcleo de Atendimento às Pessoas com Necessidades Específicas NAPNE. Rio de Janeiro, RJ, 2014. 12p. Disponível em: https://portal.ifrj.edu.br/sites/default/files/IFRJ/ConSup/Resolucoes2014/res._55__regulamento_do_napne.pdf. Acesso em: 21 jan. 2020. 
INSTITUTO FEDERAL DE EDUCAÇÃO, CIÊNCIA E TECNOLOGIA DO RIO GRANDE DO NORTE (IFRN). Deliberação no. 18/2015-CODIR/IFRN. Aprova proposta de

Regimento Interno do Núcleo de Atendimento às Pessoas com Necessidades Específicas - NAPNE do IFRN. Natal, RN, 2015. 8p. Disponível em:https://portal.ifrn.edu.br/conselhos/conselho-de-dirigentes/deliberacoes / 2015/deliberacao-no-18-2015/view. Acesso em: 21 jan. 2020.

INSTITUTO FEDERAL DE EDUCAÇÃO, CIÊNCIA E TECNOLOGIA DE RONDÔNIA (IFRO). Resolução n 30/CONSUP/IFRO, de 03 de outubro de 2011. Dispõe sobre o Regulamento dos Núcleos de Atendimento às Pessoas com Necessidades Educacionais Específicas - NAPNEs do IFRO. Porto Velho, RO, 2011. 9p. Disponível em: https://portal.ifro.edu.br/ images/Campi/ Colorado_do_Oeste/Documentos/Resolu\%C3\%A7\%C3\%A3o_n._30_-_Regulamento _NAPNE.pdf. Acesso em: 21 jan. 2020.

INSTITUTO FEDERAL DE EDUCAÇÃO, CIÊNCIA E TECNOLOGIA DE RONDÔNIA (IFRO). Parecer n 06/2017/DAE/PROEN/IFRO, de 11 de dezembro de 2017. Analisa a legislação nacional e emite parecer para a aplicação do instituto da "terminalidade específica" no âmbito do IFRO, a pedido do Campus Ji-Paraná. Porto Velho, RO, 2017. $4 p$.

\section{INSTITUTO FEDERAL DE EDUCAÇÃO, CIÊNCIA E TECNOLOGIA DE RORAIMA} (IFRR). Resolução no 429/Conselho Superior, de 06 de fevereiro de 2019. Aprova o Regulamento do Núcleo de Atendimento às Pessoas com Necessidades Educacionais Específicas - NAPNE do IFRR. Boa Vista, RR, 2019. 9p. Disponível em: https://www.ifrr.edu.br/acessoainformacao/ participacao-social/conselhos-e-orgaoscolegiados/conselho-superior/ resolucoes/resolucoes-consup-2019/ resolucao-n-0-429conselho-superior. Acesso em: 21 jan. 2020.

INSTITUTO FEDERAL DE EDUCAÇÃO, CIÊNCIA E TECNOLOGIA DO RIO GRANDE DO SUL (IFRS). Resolução no 020, de 25 de fevereiro de 2014. Aprova o Regulamento do Núcleo de Atendimento às Pessoas com Necessidades Educacionais Específicas NAPNE. Bento Gonçalves, RS, 2014. 7p. Disponível em: https://ifrs.edu.br/wpcontent/uploads/2017/09/Resolucao-20-14.pdf. Acesso em: 21 jan. 2020.

INSTITUTO FEDERAL DE EDUCAÇÃO, CIÊNCIA E TECNOLOGIA DO RIO GRANDE DO SUL (IFRS). Instrução Normativa no 12, de 21 de dezembro de 2018. Regulamento de Fluxos e Procedimentos de Identificação, Acompanhamento e Realização do Plano Educacional Individualizado (PEI) do estudantes com necessidades educacionais específicas do IFRS. Bento Gonçalves, RS, 2018. 8p. Disponível em: https://ifrs.edu.br/wp-content/uploads/2018/12/IN-PEl-21.12_Publicada_em_271218.pdf. Acesso em: 21 jan. 2020.

INSTITUTO FEDERAL DE EDUCAÇÃO, CIÊNCIA E TECNOLOGIA DE SERGIPE (IFS). Resolução no 03/2014/CS. Aprova o Regulamento Interno do Núcleo de Atendimento às Pessoas com Necessidades Específicas - NAPNE do IFS. Aracaju, SE, 2014. 7p. Disponível em:

http://www.ifs.edu.br/images/arquivos/Diae/CS_03_Aprova_o_Regulamento_interno_do_ NAPNE.pdf. Acesso em: 21 jan. 2020. 
INSTITUTO FEDERAL DE EDUCAÇÃO, CIÊNCIA E TECNOLOGIA DE DO SERTÃO PERNAMBUCANO (IFSERTÃO-PE). Resolução no $\mathbf{3 3}$ do Conselho Superior, de 03 de novembro de 2016. Aprova o Regimento Interno do Núcleo de Atendimento às Pessoas com Necessidades Especiais - NAPNE do IFSertão-PE. Petrolina, PE, 2016. 13p. Disponível em: https://www.ifsertao-pe.edu.br/images/Aluno/Assistencia-

Estudanti//NOVOSARQUIVOS/Resoluo-n--33.-Aprova-Regimento-NAPNE.pdf. Acesso em: 21 jan. 2020.

INSTITUTO FEDERAL DE EDUCAÇÃO, CIÊNCIA E TECNOLOGIA DE SÃO PAULO (IFSP). Resolução no 137, de 04 de novembro de 2014. Aprova o Regulamento do Núcleo de Apoio às Pessoas com Necessidades Educacionais Específicas - NAPNE. São Paulo, SP, 2014. 9p. Disponível em:

https://ptb.ifsp.edu.br/images/napne/Resol_137_Aprova\%20Regulamento\%20NAPNE\%20 (1).pdf. Acesso em: 21 jan. 2020.

INSTITUTO FEDERAL DE EDUCAÇÃO, CIÊNCIA E TECNOLOGIA DE SÃO PAULO (IFSP). Instrução Normativa PRE/IFSP no. 001, de 20 de março de 2017. Estabelece Orientações para Identificação e Acompanhamento, pelo NAPNE, de Estudantes com Necessidades Específicas. São Paulo, SP, 2017. 6p. Disponível em: https://www.ifspcaraguatatuba. edu.br/images/conteudo/Instrucao_Normativa_0012017_PRE_retificada.pdf. Acesso em: 21 jan. 2020.

INSTITUTO FEDERAL DE EDUCAÇÃO, CIÊNCIA E TECNOLOGIA DE SÃO PAULO (IFSP). Boletim Informativo: Avaliação em Educação Inclusiva. São Paulo, SP, 2020. 3p. Disponível em: https://pre.ifsp.edu.br/index.php?option=com_content\&view=article\&id=174:acoesinclusivas\&catid=73\&limitstart=3\&ltemid=364. Acesso em: 21 jan. 2020.

INSTITUTO FEDERAL DE EDUCAÇÃO, CIÊNCIA E TECNOLOGIA DO SUDESTE DE MINAS GERAIS (IFSUDESTEMG). Guia Orientador: ações inclusivas para atendimento ao público-alvo da educação especial no âmbito do IF Sudeste MG. Juiz de Fora, MG, 2017. 46p. Disponível em:

https://www.ifsudestemg.edu.br/documentosinstitucionais/unidades/sjdr/guia_versaoacessivel.pdf/view. Acesso em: 21 jan. 2020.

INSTITUTO FEDERAL DE EDUCAÇÃO, CIÊNCIA E TECNOLOGIA SUL-RIOGRANDENSE (IFSUL). Política de Inclusão e Acessibilidade do IFSul. Pelotas, RS, 2016. 14p. Disponível em: http://www.ifsul.edu.br/acoes-inclusivas/documentos-acoesinclusivas/item/1099-politica-de-inclusao-e-acessibilidade-do-ifsul. Acesso em: 21 jan. 2020.

INSTITUTO FEDERAL DE EDUCAÇÃO, CIÊNCIA E TECNOLOGIA SUL-RIOGRANDENSE (IFSUL). Instrução Normativa no. 03/2016. Dispõe sobre os procedimento relativos ao planejamento de estratégias educacionais a serem dispensadas aos estudantes com deficiência, tendo em vistas os princípios estabelecidos na Política de Inclusão e Acessibilidade do IFSul. Pelotas, RS, 2016a. 19p. 
INSTITUTO FEDERAL DE EDUCAÇÃO, CIÊNCIA E TECNOLOGIA DO SUL DE MINAS GERAIS (IFSULDEMINAS). Resolução no 030, de 19 de julho de 2012. Dispõe sobre a aprovação do Regimento do Núcleo de Apoio às Pessoas com Necessidades Especiais NAPNE do IFSULDEMINAS. Pouso Alegre, MG, 2012. 5p. Disponível em: https://portal.tco.ifsuldeminas.edu.br/ images/

Campus/napne/Resolucao.030.Regimento.NAPNE.pdf . Acesso em: 21 jan. 2020.

INSTITUTO FEDERAL DE EDUCAÇÃO, CIÊNCIA E TECNOLOGIA DO TRIÂNGULO MINEIRO (IFTM). Resolução no 42, de 26 de novembro de 2012. Dispões sobre a Regulamentação do Núcleo de Atendimento às Pessoas com Necessidades Educacionais Específicas - NAPNE do IFTM. Uberaba, MG, 2012. 7p. Disponível em: https://iftm.edu.br/uberaba/nap/pdf/resolucao_42_2012.pdf. Acesso em: 21 jan. 2020.

INSTITUTO NACIONAL DE ESTUDOS E PESQUISAS EDUCACIONAIS ANÍSIO TEIXEIRA (INEP). Sinopse Estatística da Educação Básica, 2019. Brasília: MEC, 2020. Disponível em: http://portal.inep.gov.br/web/guest/sinopses-estatisticas-da-educacaobasica. Acesso em: 06 ago. 2020.

\section{LIMA, Solange Rodovalho. Escolarização da pessoa com deficiência intelectual:} terminalidade específica e expectativas familiares. 2009. Tese (Doutorado em Educação Especial), Centro de Educação e Ciências Humanas- Universidade Federal de São Carlos, São Carlos/SP, 2009. Disponível em: https://repositorio.ufscar.br/bitstream/handle/ufscar/2858/2613.pdf?sequence=1. Acesso em: 03 nov. 2019.

MAGALHÃES, Joyce Goulart; CUNHA, Nathália Moreira; SILVA, Suzanli Estef. Plano Educacional Individualizado (PEI) como instrumento na aprendizagem mediada: pensando sobre práticas pedagógicas. In: GLAT, Rosana; PLETSCH, Denise (Orgs.). Estratégias educacionais diferenciadas para alunos com necessidades especiais. Rio de Janeiro: EdUERJ, 2013. p. 33-48.

MILANESI, Josiane Beltrame; MENDES, Enicéia Gonçalves. Considerações sobre a formação de professores e a educação especial e a terminalidade específica de alunos com deficiência intelectual. In: III Congresso Paranaense de Educação Especial. UNIFESSPA. Marabá/PA, 24 a 26 de novembro de 2016. Disponível em:

https://cpee.unifesspa.edu.br/images/Comunicacao_2016/CONSIDERAES_SOBRE_A_F ORMAO.pdf. Acesso em: 15 nov. 2019.

MINAYO, Maria Cecília de Souza (Org.). Pesquisa Social: teoria, método e criatividade. 34. ed. Petrópolis, RJ: Vozes, 2015.

NASCIMENTO, Franclin Costa do; FARIA, Rogério. A Questão da Inclusão na Rede Federal de Educação Profissional, Científica e Tecnológica, a partir da Ação TEC NEP. In: NASCIMENTO, Franclin Costa do; FLORINDO, Girlane Maria Ferreira; SILVA, Neide Samico da. (orgs.). Educação profissional e tecnológica inclusiva: um caminho em construção. Brasília: Instituto Federal de Educação, Ciência e Tecnologia de Brasília, 2013. p.13-23. 
NUNES, Sula Cristina Teixeira. O Programa TEC NEP: a educação profissional na perspectiva inclusiva. 2012. Trabalho de Conclusão de Curso (Pós-Graduação em Educação) - Faculdade de Educação, Universidade Federal do Rio grande do Sul, Porto Alegre, 2012. Disponível em:

http://www.lume.ufrgs.br/bitstream/handle/10183/69859/000875096.pdf?sequence=1. Acesso em: 05 nov. 2019.

OLIVEIRA, Wanessa Moreira. Ações Inclusivas no âmbito do IF Sudeste MG: um processo em construção. 2017. Dissertação (Mestrado Profissional em Diversidade e Inclusão), Instituto de Biologia - Universidade Federal Fluminense, Niterói/RJ, 2017. Disponível em: http://cmpdi.sites.uff.br/wpcontent/uploads/sites/186/2018/08/Disserta\%C3\%A7\%C3\%A3oWanessaMoreiradeOliveira19.pdf. Acesso em: 20 fev. 2020.

PEROVANO, Laís Perpetuo (Org.). Práticas Inclusivas no Ensino Técnico. Campos dos Goytacazes, RJ: Brasil Multicultural, 2019. 172p.

PERTILE, Eliane Brunetto; MORI, Nerli Nonato Ribeiro. Institutos Federais de Educação: as discussões sobre a terminalidade específica e a necessidade do atendimento educacional especializado. Revista Teoria e Prática da Educação. Maringá, v. 21, n.1, Jan./Abril, 2018. Disponível em:

http://ojs.uem.br/ojs/index.php/TeorPratEduc/article/view/45228. Acesso em: jan. 2020.

SILVA, Mariane Carloto. Processos de (re) conhecimento do estudante público-alvo da educação especial na UFSM: adaptações curriculares (des) necessárias. 2016. Dissertação (Mestrado em Educação), Programa de Pós-Graduação em Educação Universidade Federal de Santa Maria, Santa Maria/RS, 2016. Disponível em: https://repositorio.ufsm.br/handle/1/17903. Acesso em: 01 nov. 2019.

SANTOS, Thamille Pereira. Certificação por Terminalidade Específica na Rede Federal de Educação Profissional, Científica e Tecnológica: produto e produtora de representações culturais. 2019. Dissertação (Mestrado Profissional em Educação Profissional e Tecnológica), Programa de Pós-Graduação em Educação Profissional e Tecnológica Instituto Federal Farroupilha- Polo Jaguari, Santa Maria/RS, 2019. Disponível em: repositorio-dev.iffarroupilha.edu.br > bitstream > itemid Acesso em: 02 fev. 2020.

SANTOS, Juliani Natalia dos; PONCIANO, Paola Cavalheiro (Orgs.). Educação Inclusiva Sob Múltiplos Olhares: ações na Educação Profissional e Tecnológica. 1ed. Jundiaí, SP: Paco, 2019. 116p.

SILVA, Mariane Carloto; PAVÃO, Sílvia Maria de Oliveira. Terminalidade específica para estudantes com deficiência na educação superior: práticas (a serem) implementadas?

Revista Brasileira de Educação. Santa Maria, v. 24, dez. 2019. Disponível em: https://www.scielo.br/scielo.php?pid=S1413-

24782019000100241\&script=sci_arttext\&tlng=pt. Acesso em: 06 fev. 2020.

UNESCO. Educação 2030: Declaração de Incheon e Marco de Ação, rumo a uma educação de qualidade inclusiva e equitativa e à educação ao longo da vida para todos. Incheon, Coréia do Sul: UNESCO, 2015, 53p. 
http://dx.doi.org/10.5902/1984686X48006

\section{Notas}

${ }^{1}$ Nota Técnica encontrada apenas no documento referenciado.

2 Estudantes público da Educação Especial são aqueles com deficiência, transtornos globais do desenvolvimento (TGD) e altas habilidades ou superdotação, conforme definido na LDBEN (BRASIL, 1996).

3 Termo atual, adotado em substituição ao termo "deficiência mental" utilizado anteriormente e ainda presente na legislação.

${ }^{4}$ Pareceres Técnicos encontrados apenas no documento referenciado.

${ }^{5}$ IFES - Instituto Federal de Educação, Ciência e Tecnologia do Espírito Santo.

${ }^{6} \mathrm{O}$ e-Sic é um sistema eletrônico do Poder Executivo Federal na web, que visa facilitar o exercício do direito dos cidadãos de acesso às informações públicas, garantido na Lei de Acesso à Informação (BRASIL, 2011). Constitui-se um sistema de uso obrigatório para todos os órgãos e entidades do Executivo Federal para o recebimento de requerimentos de acesso à informação, conforme a Portaria Interministerial N. 1.254/2015. Objetiva organizar e facilitar o procedimento de acesso à informação, tanto para o cidadão quanto para a Administração Pública. Permite que qualquer pessoa, física ou jurídica, encaminhe pedidos de acesso à informação para órgãos e entidades do Executivo Federal, acompanhe o prazo e receba a resposta da solicitação. O acesso ao sistema é realizado por meio, da página: http://www.acessoainformacao.gov.br/

${ }^{7}$ Ressalta-se que não foram foco do presente estudo documentos de organização pedagógica e acadêmica e documentos gerais dos IFs. Foram considerados apenas documentos diretamente relacionados a políticas, programas e/ou práticas de inclusão e atendimentos aos estudantes público da EE.

8 Documentos dos IFs que foram identificados e analisados no presente estudo (constam nas referências bibliográficas): 28 Regulamento/Regimento/Diretriz/Normativa de Núcleos de Atendimento às Pessoas com Necessidades Específicas (NAPNEs) (IFAC, 2013; IFAL, 2014; IFAM, 2015; IFB, 2013; IFBAIANO, 2018; IFCE, 2015a e 2018; IFES, 2014; IFG, 2018; IFGOIANO, 2013; IFMA, 2015; IFMG, 2016; IFMS, 2016; IFMT, 2013; IFNMG, 2014 e 2019; IFPA, 2018; IFPB, 2015; IFPE, 2016; IFPI, 2014 e 2015a; IFRJ, 2014; IFRN, 2015; IFRO, 2011; IFRR, 2019; IFRS, 2014; IFS, 2014; IFSERTÃO-PE, 2016; IFSP, 2014; IFSULDEMINAS, 2012; IFTM, 2012); Políticas de Inclusão (IFBA, 2017; IFBAIANO, 2012; IFC, 2019; IFFAR, 2018; IFPI, 2015; IFSUDESTEMG, 2017; IFSUL, 2016); 7 Regulamento/Procedimento/Diretriz/Instrução Normativa para atendimento a alunos público da EE (IFAL, 2019; IFAM, 2018; IFES, 2017; IFES, 2017a, 2018; IFRS, 2018; IFSP, 2017; IFSUL, 2016a); 5 Regulamento/Normativa para o Atendimento Educacional Especializado (IFBAIANO, 2018a; IFC, 2018; IFFAR, 2019; IFGOIANO, 2016; IFMG, 2019); 4 referentes a Cartilha/Orientação/Boletim Informativo sobre ações inclusivas (IFBA, 2019; IFBA, 2020; IFPE, 2014; IFSP, 2020).

${ }^{9}$ Não foram encontrados documentos no site institucional de 4 IFs: IF Tocantins (IFTO), IF Santa Catarina (IFSC), IF Paraná (IFPR) e IF Amapá (IFAP).

10 A Rede Federal é composta por 38 IFs, 23 Escolas Técnicas Federais, 2 Centros Federais de Educação Tecnológica (CEFETs), 1 Universidade Tecnológica Federal e o Colégio Pedro II. Os IFs representam, aproximadamente, 92\% das matrículas Rede Federal (BRASIL, 2019a).

\section{Correspondência}

Wanessa Moreira de Oliveira - Instituto Federal de Educação, Ciência e Tecnologia do Sudeste de Minas Gerais, Rua Luz Interior, 360, Estrela Sul, Juiz de Fora, Minas Gerais Brasil

CEP: $36030-713$

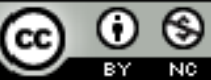

This work is licensed under a Creative Commons Attribution-NonCommercial 4.0 International (CC BY-NC 4.0) 